\title{
In Vitro Anti-Inflammatory and In Vivo Antiarthritic Activities of Aqueous and Ethanolic Extracts of Dissotis thollonii Cogn. (Melastomataceae) in Rats
}

\author{
Stephanie Flore Djuichou Nguemnang, ${ }^{1}$ Eric Gonzal Tsafack, ${ }^{1}$ Marius Mbiantcha $\mathbb{D},{ }^{1}$ \\ Ateufack Gilbert $\left({ }^{1},{ }^{1}\right.$ Albert Donatien Atsamo $\left(\mathbb{D},{ }^{2}\right.$ William Yousseu Nana, ${ }^{1}$ \\ Vanessa Matah Marthe Mba, ${ }^{1}$ and Carine Flore Adjouzem ${ }^{1}$ \\ ${ }^{1}$ Laboratory of Animal Physiology and Phytopharmacology, Department of Animal Biology, Faculty of Science, \\ University of Dschang, PO. Box 67, Dschang, Cameroon \\ ${ }^{2}$ Laboratory of Animal Physiology, Faculty of Science, University of Yaounde I, PO Box 812, Yaoundé, Cameroon \\ Correspondence should be addressed to Marius Mbiantcha; mbiantchamarius@yahoo.fr and Ateufack Gilbert; \\ ateufack2000@yahoo.fr
}

Received 15 July 2019; Accepted 1 November 2019; Published 15 November 2019

Academic Editor: Jae Youl Cho

Copyright (C) 2019 Stephanie Flore Djuichou Nguemnang et al. This is an open access article distributed under the Creative Commons Attribution License, which permits unrestricted use, distribution, and reproduction in any medium, provided the original work is properly cited.

\begin{abstract}
Dissotis thollonii Cogn. (Melastomataceae) is a tropical plant widely used in traditional Cameroonian medicine to relieve and treat many pathologies. It is widespread in the western region where it is used to treat typhoid fever, gastrointestinal disorders, and inflammatory diseases. The purpose of this study is to scientifically demonstrate the anti-inflammatory and antiarthritic properties of the aqueous and ethanolic extracts of the leaves of Dissotis thollonii. The anti-inflammatory properties were evaluated in vitro by inhibition tests for cyclooxygenase, 5-lipoxygenase, protein denaturation, extracellular ROS production, and cell proliferation; while antiarthritic properties were evaluated in vivo in rats using the zymosan A-induced monoarthritis test and the CFA-induced polyarthritis model. This study shows that aqueous and ethanolic extracts at a concentration of $1000 \mu \mathrm{g} / \mathrm{ml}$ inhibit the activity of cyclooxygenase $(47.07 \%$ and $63.36 \%)$ and 5-lipoxygenase $(66.79 \%$ and $77.7 \%)$ and protein denaturation $(42.51 \%$ and $44.44 \%)$. Similarly, both extracts inhibited extracellular ROS production $\left(\mathrm{IC}_{50}=5.74 \mu \mathrm{g} / \mathrm{ml}\right.$ and $2.96 \mu \mathrm{g} / \mathrm{ml}$ for polymorphonuclear leukocytes, $7.47 \mu \mathrm{g} / \mathrm{ml}$ and $3.28 \mu \mathrm{g} \mathrm{ml}$ for peritoneal macrophages of mouse) and cell proliferation ( $\mathrm{IC}_{50}=16.89 \mu \mathrm{g} / \mathrm{ml}$ and $3.29 \mu \mathrm{g} /$ $\mathrm{ml})$. At a dose of $500 \mathrm{mg} / \mathrm{kg}$, aqueous and ethanolic extracts significantly reduce edema induced by zymosan A (69.30\% and $81.80 \%)$ and CFA (71.85\% and 79.03\%). At the same dose, both extracts decreased sensitivity to mechanical hyperalgesia with $69.00 \%$ and $70.35 \%$ inhibition, respectively. Systemic and histological analyzes show that both extracts maintain the studied parameters very close to normal and greatly restored the normal architecture of the joint in animals. Dissotis thollonii would therefore be a very promising source for the treatment of inflammatory diseases.
\end{abstract}

\section{Introduction}

Rheumatoid arthritis (RA) is a chronic, disabling, and progressive autoimmune disease in which chronic proliferative synovitis and synovial inflammation arde observed with significant bone destruction and cartilage destruction resulting in significant joint damage and reduced functionality [1-3]. This pathology can evolve very quickly in an individual and affect several parts of the body that become inflamed or extremely painful particularly affecting the elderly, but also individuals with degenerative bone disorder or immune system dysfunction [4]. This pathology, which can also occur as a result of the immune system attacking the synovial membrane, is accompanied by swelling, stiffness, pain, and a reduction or loss of joint function [4]. During the establishment and development of rheumatoid arthritis, many inflammatory mediators play a key role in bone destruction and inflammation of the synovial membrane, 
including tumor necrosis factor (TNF- $\alpha$ ), interleukin- $1 \beta$, interleukin-6, nitric oxide (NO), prostaglandins, reactive oxygen species (ROS), platelet-activating factor, leukotrienes, enzymes (lipoxygenases, cyclooxygenases (COX-1 and COX-2), and phospholipases) [5, 6].

Animal models of zymosan A-induced monoarthritis and Freund's complete adjuvant-induced polyarthritis (CFA) are widely used in research for the activity of many pharmacological substances on rheumatoid arthritis. In fact, the injection of zymosan into the knee joint of the rats causes erosive synovitis with increased vascular permeability, neutrophil infiltration, and formation of edemas and exudates in the acute phase, and then in the chronic phase, infiltration of macrophages and lymphocytes, pannus formation, and fibroblastic reaction characteristic of chronic rheumatoid synovitis $[7,8]$. CFA is an immunogenic adjuvant consisting of a suspension of Mycobacterium tuberculosum or Mycobacterium butyricum killed by heat. When injected at the base of the animal's tail, it causes the development of polyarthritis that evolves in a two-phase cycle of time: the first phase appears in a few hours and disappears after 3 to 5 days and manifests itself by an acute local inflammatory reaction, and then the second phase appears after two weeks and corresponds to a chronic systemic reaction [9-11]. This polyarthritis is not primarily aimed at the knee joint, and it can affect the general state of the animal body; it is a real systemic disease resulting in inflammation of the distal joints of the limbs, vertebrae, lesions of the genitourinary tract, gastrointestinal tract, eyes, nose, ears, skin, and anorexia accompanied by significant weight loss $[9,11]$. In addition, the pathology will persist, and other symptoms will appear, namely, joint deformity, synovitis, synovial hyperplasia, capsular fibrosis, angiogenesis, pannus formation, cartilage destruction, bone erosion, inflammation of the bone marrow, resorption of bone matrix, and ankylosis [12].

The severity and persistence of rheumatoid arthritis require long-term management with anti-inflammatory drugs. Nevertheless, these anti-inflammatory drugs have for the most part risks of toxicity for long-term use, which seriously limits their use. Current research in the management of rheumatoid arthritis is turning to a new generation of substances capable of selectively inhibiting TNF alpha and/or cyclooxygenase (COX-2) and having no major side effects [13]. Recent interest in alternative treatments for arthritis favors the use of traditional medicine although scientific evidence of efficacy for most cases is lacking. Nevertheless, several herbs, used in a care program and a very effective preventive medicine, can act individually and/ or in synergy to reduce chronic joint inflammation (osteoarthritis and/or rheumatoid arthritis) [14-16]. To reach the total health care coverage of the world's population, traditional medicine is considered by WHO to be the most effective means since about $25 \%$ of modern prescription drugs are more or less obtained from plants [17, 18].

Comprising about 163 genera, the family of Melastomataceae which are mainly pantropical plants include more than 4,300 species so many of them are known for their effectiveness in traditional medicine as antihepatitic, antihypertensive, anti-inflammatory, antihyperglycaemic, antioxidant, hemostatic, and antidiarrheal [19-24]. Dissotis thollonii (D. thollonii) is one of many species of the family of Melastomataceae used in traditional medicine in Cameroon to treat typhoid fever, gastrointestinal disorders, inflammatory diseases, and sinusitis [25-27]. The leaves are recommended for the treatment of ulcers and gastrointestinal disorders. A previous study showed that D. thollonii significantly inhibited fluid accumulation in intestine induced by prostaglandin E2 [28]. Based on recent work by Ateufack et al. [29], this plant has antidiarrheic and antibacterial properties and then has several secondary metabolites including tannins, flavonoids, sterols, anthraquinones, phenols, and polyphenols. In addition, the work of TadjouaTchoumbou et al. [24] showed that this plant significantly inhibited leukocyte migration in peritoneal fluid, intracellular ROS production, proliferation of Hela cell lines, and TNF- $\alpha$ production. Tala et al. [27] showed that aqueous and ethanolic extracts were devoid of toxicity after 28 days of daily treatment. Similarly, Nono et al. [30] showed the antimicrobial and antioxidant properties of this plant. Several compounds have already been isolated from this plant, among which $3,3^{\prime}$-diomethylellagic acid $4^{\prime}-\mathrm{O}-\beta$-D-xylopyranoside, $3-4^{\prime}-\mathrm{O}-\beta$-Darabinopyranoside, casuarinine, betulinic acid, $\beta$-sitosterol3-O-D-glucopyranosyl-6' -mirystate, cellobiosylsterol, $\beta$-sitosterol, $\beta$-sitosterol-3-O- $\beta$-D-glucopyranoside, arjunolic acid, 3,3'-diomethylellagic acid, ellagic acid, and 3,3' -diomethylellagic acid $4^{\prime}$-O- $\beta$-D-glucopyranoside [30]. Although this plant is traditionally used to relieve many disorders of the body, no information or scientific report to our knowledge has been found in the literature relative to its antiarthritic properties. In our continuous search for bioactive extracts from plants used in traditional Cameroonian medicine [31,32], and in order to support and improve the traditional use of $D$. thollonii, we undertook to carry out the present study on in vitro anti-inflammatory activities and in vivo antiarthritic activities of the leave extracts of $D$. thollonii.

\section{Materials and Methods}

2.1. Plant Material and Extraction. The plant material, referenced to the national herbarium of Cameroon under the number $\mathrm{N}^{\circ} 133292 / \mathrm{SRF}$ Cam, in the name of D. thollonii (Melastomotaceae) was used in this study. The fresh leaves were harvested in the town of Dschang (western Cameroon), dried in the shade, and then crushed into a fine powder. In order to prepare the aqueous extract, $500 \mathrm{~g}$ of powder was mixed into $500 \mathrm{ml}$ of distilled water during 72 hours and filtrated (Whatman paper No. 4); the filtrate obtained was evaporated at $40^{\circ} \mathrm{C}$ to give the aqueous extract ( $8.2 \%$ yield). The same weight of dried powder plant was mixed into $500 \mathrm{ml}$ of ethanol for 72 hours and then filtered. The filtrate was concentrated with a rotary evaporator set at $96^{\circ} \mathrm{C}$ to give the ethanolic extract with $9.6 \%$ yield.

2.2. Phytochemical Assay of D. thollonii Extracts. The different extracts were subjected to chemical screening in order 
to detect the presence of the main groups of compounds following the principles stated by Matos [33].

2.3. Triterpenes and Steroids: Lieberman-Burchard Test. In a tube containing $3 \mathrm{ml}$ of $\mathrm{MeOH}, 0.1 \mathrm{~g}$ of extracts was dissolved, and then $0.2 \mathrm{ml}$ of each of the following reagents was added: chloroform, glacial acetic anhydride, and concentrated $\mathrm{H}_{2} \mathrm{SO}_{4}$. The mixture was observed to look for the appearance of the greenish-blue or purple-pink color characteristics of the presence of sterols and triterpenes, respectively.

2.4. Phenols. The tube contained $3 \mathrm{ml}$ of ethanol; $0.1 \mathrm{~g}$ of extracts was dissolved, and then three drops of $10 \%$ iron III chloride were added. The solution was then observed to observe for the appearance of the blue-violet or greenish coloration which characterizes the presence of the phenols.

2.5. Tannins. $5 \mathrm{ml}$ of $\mathrm{MeOH}$ was introduced in the tube, and $0.1 \mathrm{~g}$ of extracts was dissolved. The solution was then added with 5 drops of $0.5 \%$ sulfuric acid, and the mixture was observed to detect the green or blue-black color, indicating the presence of tannins.

2.6. Flavonoids: Shinoda Test. In a tube containing $3 \mathrm{ml}$ of $\mathrm{MeOH}, 0.1 \mathrm{~g}$ of extracts was dissolved, and the mixture was then treated with $0.05 \mathrm{~g}$ of magnesium chloride chips and 3 drops of concentrated $\mathrm{H}_{2} \mathrm{SO}_{4}$. The flavonoids were highlighted by the appearance of the following colorings: orange for flavones, red for xanthones, and pink for flavonols.

2.7. Anthocyanings. In a test tube containing $0.1 \mathrm{~g}$ of extracts, 5 drops of concentrated hydrochloric acid were introduced. The solution was then observed to look for the appearance of red color indicating the presence of anthocyanins.

2.8. Saponins. The presence of saponins is generally materialized by the formation of a stable foam after stirring a solution. Thus, a solution of $5 \mathrm{ml}$ of distilled water and $5 \mathrm{ml}$ of each extract was vigorously shaken to check for the presence or absence of saponins in each extract of our plant.

2.9. Anthraquinone. The presence of free anthraquinones and/or anthraquinone derivatives in a mixture is indicated by a pink, violet, or red coloration in the lower phase (ammoniacal phase) of the mixture after stirring. Thus, two methods made it possible to verify the presence of this class of compound in our various extracts:

(i) Stirring a solution prepared in the following manner: extract $(3 \mathrm{ml})$ and benzene $(3 \mathrm{ml})$, followed by filtration and then $5 \mathrm{ml}$ ammonia $(10 \%)$ in the filtrate.

(ii) A mixture of extract $(3 \mathrm{ml})$ and sulfuric acid $(3 \mathrm{ml})$ is boiled and filtered while hot and benzene $(3 \mathrm{ml})$ is added to the filtrate followed by stirring. After separation of the benzene layer, ammonia prepared at $10 \%(3 \mathrm{ml})$ was added.

\section{In Vitro Anti-Inflammatory Assays}

3.1. Inhibition of Protein Denaturation. To evaluate the antiinflammatory effects of the extracts, the protocol described by Padmanabhan and Jangle [34] and Elias and Rao [35] was used with small modifications. A volume of $1 \mathrm{ml}$ of extracts (aqueous and ethanolic) or of diclofenac sodium at different concentrations $(100,200,500$, and $1000 \mu \mathrm{g} / \mathrm{ml})$ was homogenised with $1 \mathrm{ml}$ of aqueous solution of bovine serum albumin (5\%) and incubated at $27^{\circ} \mathrm{C}$ for 15 minutes. The mixture of distilled water and BSA constituted the control tube. Denaturation of the proteins was caused by placing the mixture in a water bath for 10 minutes at $70^{\circ} \mathrm{C}$. The mixture was cooling inside the ambient room temperature, and the activity each mixture was measured at $660 \mathrm{~nm}$. Each test was done three times. The following formula was used to calculated inhibition percentage:

$$
\% \text { inhibition }=\frac{\text { absorbance of control }- \text { absorbance of sample }}{\text { absorbance of control }} \times 100 \text {. }
$$

\section{Assay of Cyclooxygenase and 5-Lipoxygenase Inhibition}

4.1. Lymphocyte Culture Preparation. RPMI 1640 (HIMEDIA) added with inactivated fetal calf serum, penicillin, and streptomycin was used for culture of human peripheral lymphocytes, and cell proliferation was induced by phytohemagglutinin (HIMEDIA). After filtration (using 0.2 micron cellulose acetate, Sartorios), plasma was added $\left(1 \times 10^{6}\right.$ cells $\left./ \mathrm{ml}\right)$ and incubated for 72 hours, and the culture was activated by the addition of lipopolysaccharide $(1 \mu \mathrm{l})$ and incubated again for 24 hours. Extracts (aqueous and ethanolic) and ibuprofen were added at a final concentration of $100,200,500$, and $1000 \mu \mathrm{g} / \mathrm{ml}$, incubated for 24 hours, and centrifuged for sedimentation at $6000 \mathrm{rpm}$ for $10 \mathrm{~min}$. After removal of the supernatant, cell lysis buffer was added $(50 \mu \mathrm{l})$, and the mixture was again centrifuged at $6000 \mathrm{rpm}$ for $10 \mathrm{~min}$. The anti-inflammatory test was performed according to the method used by Viji and Helen [36].

4.2. Assay of Cyclooxygenase. A mixture of glutathione, tris$\mathrm{HCl}$ buffer, enzyme, and hemoglobin was used to make the assays. After addition of arachidonic acid and TCA (10\% in $1 \mathrm{~N} \mathrm{HCl}, 0.2 \mathrm{ml})$, the mixture was incubated at $37^{\circ} \mathrm{C}(20$ minutes). The TBA $(0.2 \mathrm{ml})$ was added to the contents which were then heated (for 20 minutes in boiling water), and after cooling, the mixture was centrifuged (1000 rpm, $3 \mathrm{~min}$ ) and the supernatant was used to measure COX activity at $632 \mathrm{~nm}$ [36].

4.3. Assay of 5-Lipoxygenase. In $4 \mathrm{ml}$ of nonoxygenated water, linoleic acid (70 mg) and an equal weight of interpolation were dissolved and pipetted, followed by sodium 
hydroxide $(0.5 \mathrm{~N})$ and water without oxygen $(25 \mathrm{~mL})$ was added. The final solution was divided into small portions of $0.5 \mathrm{ml}$ each and rinsed with nitrogen and frozen. A quartz cuvette $\left(25^{\circ} \mathrm{C}\right)$ optical path of $1 \mathrm{~cm}$ made it possible to carry out the reaction. The OD measured at $234 \mathrm{~nm}$ was performed with a mixture of tris buffer $(2.75 \mathrm{ml}, \mathrm{pH} 7.4)$, sodium linoleate $(0.2 \mathrm{ml})$, and enzyme $(50 \mathrm{ml})$ [36]. The following formula was served to determine percent inhibition:

$$
\% \text { inhibition }=\left[\frac{\{\text { abs control }- \text { abs sample }\}}{\text { abs control }}\right] \times 100 \text {. }
$$

4.4. Chemiluminescence Assay. The human blood samples used in this work were received from a donor following the procedure accepted by the Independent Ethics Committee, ICCBS, University of Karachi, No : ICCBS/IEC-008-BC2015/Protocol/1.0. The blood donors were informed that it should be used for an experimental study.

\subsection{Isolation of Human Polymorphoneutrophils (PMNs).} Aseptically, a volume of $10 \mathrm{ml}$ of venous blood was taken from a very healthy 33-year-old volunteer donor and then introduced into a tube with anticoagulant (heparin). Neutrophils were isolated following the protocol described by hypoflat Ficoll density gradient centrifugation [37]. For this, in an empty tube of $45 \mathrm{ml}$, the whole blood, HBSS, and LSM (lymphocyte separation medium) were introduced at equal volume, and after $30 \mathrm{~min}$ latency, the supernatant of this mixture was then removed and introduced into a $15 \mathrm{ml}$ tube previously containing $5 \mathrm{ml}$ of LSM; then, the tube was centrifuged at $400 \mathrm{~g}$ for 20 minutes (room temperature). After removal of the supernatant, $1 \mathrm{ml}$ of distilled water was introduced into the tube (for lysis of red blood cells); after a duration of 1 minute, the HBSS $(2 \mathrm{x})$ (1 ml) was also introduced (to stop the lysis). After adding $5 \mathrm{ml}$ of HBSS again, the tube was centrifuged for 10 minutes at $4^{\circ} \mathrm{C}$ $(300 \mathrm{~g})$, and $1 \mathrm{ml}$ of HBSS was added after removal of the supernatant and the tube was kept in ice. The trypan blue technique was used to assess viability while the hemocytometer counted the cells. For each test, the cell concentration used was $1 \times 10^{6}$ cells $/ \mathrm{ml}$.

4.6. Peritoneal Macrophage Isolation from Mice. One milliliter of FBS was injected (intraperitoneally) into NMRI mice weighing an average of $22 \mathrm{~g}$, and these animals were kept and observed for 3 days; then, they underwent cervical dislocation for sacrifice. The RPMI medium $(10 \%, 10 \mathrm{ml})$ was introduced into the peritoneal cavity, after 2 minutes of massage, the skin of the abdomen was removed, and the peritoneal cavity was exposed. Using a syringe, the RPMI medium injected into the peritoneum and containing the macrophages was removed, introduced into a tube, centrifuged $\left(400 \mathrm{~g}, 20\right.$ minutes, $4^{\circ} \mathrm{C}$ ), the supernatant was removed, $5 \mathrm{ml}$ incomplete RPMI was supplemented, the tube was further centrifuged $\left(300 \mathrm{~g}, 10\right.$ minutes, $4^{\circ} \mathrm{C}$ ), and then RPMI/HBSS $(1 \mathrm{ml})$ was supplemented. The trypan blue technique was used to assess viability, while the hemocytometer counted the cells. For each test, the cell concentration used was $1 \times 10^{6}$ cells/ml $[38,39]$.

For the chemiluminescence assay, the modified protocol of Mbiantcha et al. [40] was used. In white plates (96 wells), $25 \mu \mathrm{l}$ of PMNs cells, whole blood or macrophages, $25 \mu \mathrm{l}$ of extracts (aqueous or ethanolic), or ibuprofen were mixed. While the well without extracts represent the control and received only cells and $\mathrm{HBSS}^{++}$. After 20 minutes of incubation, each well obtained $25 \mu \mathrm{l}$ of luminol and $25 \mu \mathrm{l}$ of PMA, which made it possible to obtain a total volume of $100 \mu \mathrm{l}$ in each well. After completing this test, the results were expressed in RLU (relative light units), and the following formula allowed to calculate the percentage of inhibition:

$$
\text { inhibition }(\%)=\frac{(\text { RLUcontrol }- \text { RLUsample })}{\text { RLUcontrol }} \times 100 \text {. }
$$

4.7. T-Cell Proliferation Assay [41]. 96-well white plates were used for this test. In each well, were introduced the extracts (2, 10 and $50 \mu \mathrm{g} / \mathrm{ml}$ ), prednisolone (diluted in RPMI (5\%)), $50 \mu \mathrm{l}$ of T lymphocytes at a concentration of $2 \times 10^{6}$ cells $/ \mathrm{ml}$, $50 \mu \mathrm{l}$ of PHAL at a concentration of $7.5 \mu \mathrm{g} / \mathrm{ml}$ (phytohemagglutinin-L). Wells considered as negative controls received only $550 \mu \mathrm{l}$ of cells and $150 \mu \mathrm{l}$ of RPMI (5\%), whereas those considered as positive controls received $50 \mu \mathrm{l}$ of cells, $50 \mu \mathrm{l}$ of PHA, and $100 \mu \mathrm{l}$ of RPMI (5\%). The plates were then incubated ( 3 days, $37^{\circ} \mathrm{C}, \mathrm{CO}_{2}(5 \%)$ ), $25 \mu \mathrm{l}$ of $0.5 \mu \mathrm{Ci} /$ well (methyl $73 \mathrm{H}$ ) thymidine was used to pulse the cultures, followed by a second incubation for 18 hours, and then the cells were harvested (using a fiberglass filter). The level of thymidine integrated in the cells was determined using a counter (LS65000 liquid scintillation). The following formula allowed to calculate the percentage of inhibition using CPM (counts per minute):

$$
\text { inhibitory activity }(\%)=\frac{(\text { CPMcontrol }- \text { CPMsample })}{\text { CPMcontrol }} \times 100 \text {. }
$$

\section{In Vivo Antiarthritis Assays}

5.1. Animals. Female Wistar rats ( 3 to 4 months old and 150 to $200 \mathrm{~g}$ ) were used for these tests. The animals were breeded from the faculty of science (laboratory of animal physiology and phytopharmacology) of the University of Dschang (Cameroon). They were raised under normal conditions (19-23 ${ }^{\circ} \mathrm{C}, 12$ hour light) with water and access without diet.

The experimental procedures have been approved by the local Ethics Committee and are in accordance with the guidelines for the study of pain in awake animals, published by the NIH (publication no. 85-23, "Principles of Animal Protection," Laboratory, and Study of Pain, Ministry of Scientific Research and Technology, which adopted the European Union Guidelines on Animal Care and Experimentation (EWC 86/609).

5.2. Treatment Regimen. Animals were grouped by their weight into different cages, and in each group, they were 
identified by the tail with a number using a marker pen. In each test, 42 female rats were divided into 7 groups (6 rats each): group 1 (healthy control) received no treatment and no injection of zymosan A (Sigma Chemical Co., St. Louis, Missouri, USA) or CFA (Sigma Chemical Co., St. Louis, Missouri, USA), group 2 (arthritic control group) received the solution of DMSO (5\%) + PBS with injection of zymosan A or CFA, group 3 (positive control) received diclofenac $(5 \mathrm{mg} / \mathrm{kg}$ ) with injection of zymosan A or CFA, groups 4 and 5 received the aqueous extract of $D$. thollonii ( 250 and $500 \mathrm{mg} / \mathrm{kg}$ ) with injection of zymosan A or CFA, and groups 6 and 7 received the ethanolic extract of D. thollonii (250 and $500 \mathrm{mg} / \mathrm{kg}$ ) with injection of zymosan A or CFA. All treatments were administered orally 1 hour before the induction of zymosan A or CFA (day 0), and then the animals were treated daily for 5 days for zymosan A-induced monoarthritis and 35 days for polyarthritis induced by the CFA.

5.3. Monoarthritis Induced by Zymosan. In this test, the protocol of Mbiantcha et al. [31] has been used with some modifications. One hour after oral administration of the various treatments, the thiopental is injected into each animal $(0.1 \mathrm{ml} / 100 \mathrm{~g}$, intraperitoneal route), and then $\mathrm{zy}$ mosan A $(0.3 \mathrm{ml}, 0.9 \% \mathrm{v} / \mathrm{v} \mathrm{NaCl})$ was injected in the knee joint using a digital caliper (Mitutoyo, Japan); before the oral treatment, the thickness of the injected joint was measured, and then $1,2,3,4,5,6,24,48,72,96$, and $120 \mathrm{~h}$ after the injection of zymosan A. On the fifth day after taking the last parameters, the animals were again anesthetized, and the injected knee joint was incised and preserved in a formalinPBS mixture (10\%). The general scheme of method in histology was followed for histological analysis.

5.4. Polyarthritis Induced by CFA. The modified protocol of Mbiantcha et al. [40] was used. One hour after administration of each treatment, the animals were anesthetized by inhalation of ether vapor, and then $100 \mu \mathrm{l}$ of CFA $(10 \mathrm{mg} / \mathrm{ml})$ was injected into the tail vein, and then the animals were returned to well-labeled cages and observed.

The severity of arthritis was assessed by measuring the thickness of the hind leg joint using a digital caliper (days 0, 1, $3,5,7,9,11,13,15,17,19,21,23,25,27,29,31,33$, and 35), the pain sensitivity threshold using an analgesimeter (days 2, 4, 6, $8,10,12,14,16,18,20,22,24,26,28,30,32$, and 34$)$, and the arthritic score every day with certain criteria (score $0=$ normal state, score $1=$ edema on one foot or nodule, score $2=$ two feet with edema or paw and nodule tail, score $3=$ two feet with edema and nodosity of the tail or three feet with edema, and score $4=$ three feet with edema and nodosity of tail or edema of four feet) and body weight every week.

At day 36, the animals were anesthetized with thiopental ( $0.1 \mathrm{ml} / 100 \mathrm{~g}$ body weight), the blood was removed by catheterization of the abdominal artery and introduced into two different types of tubes; tubes containing EDTA as anticoagulant for analysis of hematological parameters by standard laboratory method and tubes containing no anticoagulant were centrifuged (4900 rpm, 5 minutes), serum was collected to evaluate ALT, AST, ALP, MDA, creatinine, total protein, and stress parameters (NO, MAD, SOD, catalase, and glutathione). The weights of various organs such as liver, kidneys, thymus, and spleen were weighed, and knee joints of all animals were collected and stored in a formalin-PBS mixture (10\%) for histological analysis.

5.5. Statistical Analysis. All in vitro test data indicate mean \pm standard deviation in triplicate while for the in vivo test, the data are presented as an average of 6 animals \pm SEM. Differences between groups were assessed by ANOVA (one way and two way) followed by Bonferroni posttest. Significant differences were considered at $p<0.05 . a, b$, and $c$ or $\alpha$, $\beta$, and $\lambda$ denote significant differences with respect to the healthy control group and/or the arthritic control group.

\section{Results}

6.1. Chemical Composition. Several groups of chemical compounds have been demonstrated in extracts of $D$. thollonii. It can be seen from this table that the ethanolic extract contains all the test compounds with the exception of anthocyanins and triterpenes, whereas the aqueous extract contains only flavonoids, phenols, and polyphenols (Table 1).

\section{In Vitro Anti-Inflammatory Activity}

7.1. Inhibition of Protein Denaturation. For the results of this study, aqueous and ethanolic extracts effectively inhibit protein denaturation (albumin) caused by heat. Table 2 shows significant inhibition $(p<0.001)$ of $42.51 \%$ and $44.44 \%$, respectively, for the aqueous extract and the ethanolic extract at a concentration of $1000 \mu \mathrm{g} / \mathrm{ml}$, whereas diclofenac sodium produced $89.19 \%$ inhibition.

7.2. Cyclooxygenase Inhibitory Assay. Evaluation of cyclooxygenase activity determined the effect of both extracts on prostaglandin production. The results show that, at $1000 \mu \mathrm{g} /$ $\mathrm{ml}$, the aqueous extract, the ethanolic extract, and ibuprofen significantly $(p<0.001)$ inhibit the activity of cyclooxygenase with $47.07 \%, 63.36 \%$, and $97.88 \%$, respectively (Table 2).

7.3. 5-Lipoxygenase Inhibitory Assay. The evaluation of the activity of 5-lipoxygenase was used to study the effect of the various extracts on the production of leukotrienes. This table shows that the aqueous and ethanolic extracts, as well as ibuprofen, have a significant inhibitory effect $(p<0.001)$ on the activity of 5-lipoxygenase with $66.79 \%$ inhibition, $77.48 \%$ and $95.31 \%$, respectively (Table 2 ).

7.4. Effect of D. thollonii on Production of Intracellular ROS and T-Cell Proliferation. Table 3 presents the results for extracellular ROS production and T-cell proliferation. PMA is used to activate ROS and luminol as a developer. The ethanolic extract of $D$. thollonii significantly inhibited the release of ROS in whole blood with an $\mathrm{IC}_{50}$ of $4.98 \mu \mathrm{g} / \mathrm{ml}$. In the presence of polymorphonuclear, an inhibition was 
TABle 1: Phytochemical profile of Dissotis thollonii.

\begin{tabular}{lllllllll}
\hline \multirow{2}{*}{ Extracts } & \multicolumn{9}{c}{ Phytochemical compounds } \\
& 1 & 2 & 3 & 4 & 5 & 6 & 7 & 8 \\
\hline Aqueous extract & - & - & - & + & - & - & + & + \\
Ethanolic extract & - & + & + & + & - & + & + & + \\
\hline
\end{tabular}

-: absent; +: present; 1: triterpenoids; 2: sterols; 3: tannins; 4: flavonoids; 5: anthocyanings; 6: anthraquinones; 7: phenol/polyphenol; 8: saponins; 9: cardiac glycosides.

TABLE 2: Effect of aqueous and ethanolic extracts of Dissotis thollonii on protein denaturation, cyclooxygenase inhibition, and 5-lipoxygenase inhibition.

\begin{tabular}{|c|c|c|c|c|}
\hline \multirow{2}{*}{ Compounds } & \multirow{2}{*}{ Dose $(\mu \mathrm{g} / \mathrm{ml})$} & \multicolumn{3}{|c|}{ Inhibition (\%) } \\
\hline & & Protein denaturation & Cyclooxygénase & 5-lipoxygénase \\
\hline \multirow{4}{*}{ Diclofenac } & 100 & 74.41 & - & - \\
\hline & 200 & 76.72 & - & - \\
\hline & 500 & 81.48 & - & - \\
\hline & 1000 & 89.19 & - & - \\
\hline \multirow{4}{*}{ Ibuprofen } & 100 & - & 83.46 & 82.03 \\
\hline & 200 & - & 89.90 & 88.63 \\
\hline & 500 & - & 93.39 & 92.96 \\
\hline & 1000 & - & 97.88 & 95.31 \\
\hline \multirow{4}{*}{ Aqueous extract } & 100 & 27.33 & 24.72 & 31.26 \\
\hline & 200 & 29.26 & 34.14 & 45.60 \\
\hline & 500 & 33.83 & 40.70 & 58.17 \\
\hline & 1000 & 42.51 & 47.07 & 66.79 \\
\hline \multirow{4}{*}{ Ethanolic extract } & 100 & 30.87 & 28.14 & 36.12 \\
\hline & 200 & 32.79 & 40.89 & 48.24 \\
\hline & 500 & 37.30 & 53.55 & 64.11 \\
\hline & 1000 & 44.44 & 63.36 & 77.48 \\
\hline
\end{tabular}

The percentage values were obtained using various concentrations of test compounds, and readings are presented as mean of triplicates.

TABLE 3: $\mathrm{IC}_{50}$ value of aqueous and ethanolic extracts of Dissotis thollonii on human whole blood evaluated by luminal-amplified chemiluminescence.

\begin{tabular}{|c|c|c|c|c|}
\hline & \multicolumn{3}{|c|}{ Oxidative burst $\left(\mathrm{IC}_{50}(\mu \mathrm{g} / \mathrm{ml})\right)$} & \multirow{2}{*}{ T-cell proliferation $\left(\mathrm{IC}_{50}(\mu \mathrm{g} / \mathrm{ml})\right)$} \\
\hline & WB & PMNs & MQ & \\
\hline Aqueous extract & $>100$ & $5.74 \pm 0.65$ & $7.47 \pm 2.68$ & $16.89 \pm 2.55$ \\
\hline Ethanolic extract & $4.89 \pm 0.49$ & $2.96 \pm 0.12$ & $3.28 \pm 0.09$ & $3.29 \pm 1.96$ \\
\hline Ibuprofen & $12.71 \pm 0.13$ & $12.53 \pm 0.21$ & $13.28 \pm 1.07$ & - \\
\hline Prednisolone & - & - & - & $<3.10$ \\
\hline
\end{tabular}

The $\mathrm{IC}_{50}$ values were obtained using various concentrations of test compounds, and readings are presented as mean \pm SD of triplicates. WB: whole blood; PMNs: polymorphonuclear leukocytes; MQ: mice peritoneal macrophages.

observed with an $\mathrm{IC}_{50}$ of $5.74 \mu \mathrm{g} / \mathrm{ml}$ and an $\mathrm{IC}_{50}$ of $2.96 \mu \mathrm{g} /$ $\mathrm{ml}$ with aqueous and ethanolic extracts. These extracts again inhibited the ROS produced by the macrophages with an $\mathrm{IC}_{50}$ of $7.47 \mu \mathrm{g} / \mathrm{ml}$ for the aqueous extract and an $\mathrm{IC}_{50}$ of $3.28 \mu \mathrm{g} / \mathrm{ml}$ for the ethanolic extract.

With respect to T-cell proliferation, both extracts showed significant antiproliferative property. Table 3 shows that the aqueous extract has an antiproliferative activity with an $\mathrm{IC}_{50}$ of $16.86 \mu \mathrm{g} / \mathrm{ml}$, while the ethanolic extract is $3.29 \mu \mathrm{g} /$ $\mathrm{ml}$ and that of prednisolone is less than $3.10 \mu \mathrm{g} / \mathrm{ml}$.

\section{In Vivo Antiarthritis Assays}

8.1. Effect of D. thollonii Treatment on Monoarthritis Induced by Zymosan $A$ in Rats. After injection of zymozan A in articulation of rats, knee joint results in the significant growth $(p<0.001)$ in the articular diameter, which is maximal from the first hour and still from the fifth day after the administration of zymosan A (Figure 1). Ethanolic and aqueous extracts of $D$. thollonii leaves (250 and $500 \mathrm{mg} / \mathrm{kg}$ ) significantly $(p<0.05)$ inhibited zymosan A-induced edema. The inhibition of edema caused by the injection of the zymosan A was significant $(p<0.01)$ from the 3 rd hour with a percentage inhibition of $52.90 \%$ for the ethanolic extract $(500 \mathrm{mg} / \mathrm{kg}$ ) and from the 4 th hour with the aqueous extract $(33.30 \%, p<0.05$, $500 \mathrm{mg} / \mathrm{kg}$ ) and diclofenac $(36.30 \%, p<0.01,5 \mathrm{mg} / \mathrm{kg})$. The maximum and significant inhibitory effect $(p<0.001)$ was observed at the 5th day for the ethanolic extract $(81.80 \%$, $500 \mathrm{mg} / \mathrm{kg})$, at the $5^{\text {th }}$ day for the aqueous extract $(69.30 \%$, $500 \mathrm{mg} / \mathrm{kg}$ ), and at day 3 for diclofenac $(53.10 \%, 5 \mathrm{mg} / \mathrm{kg})$. 


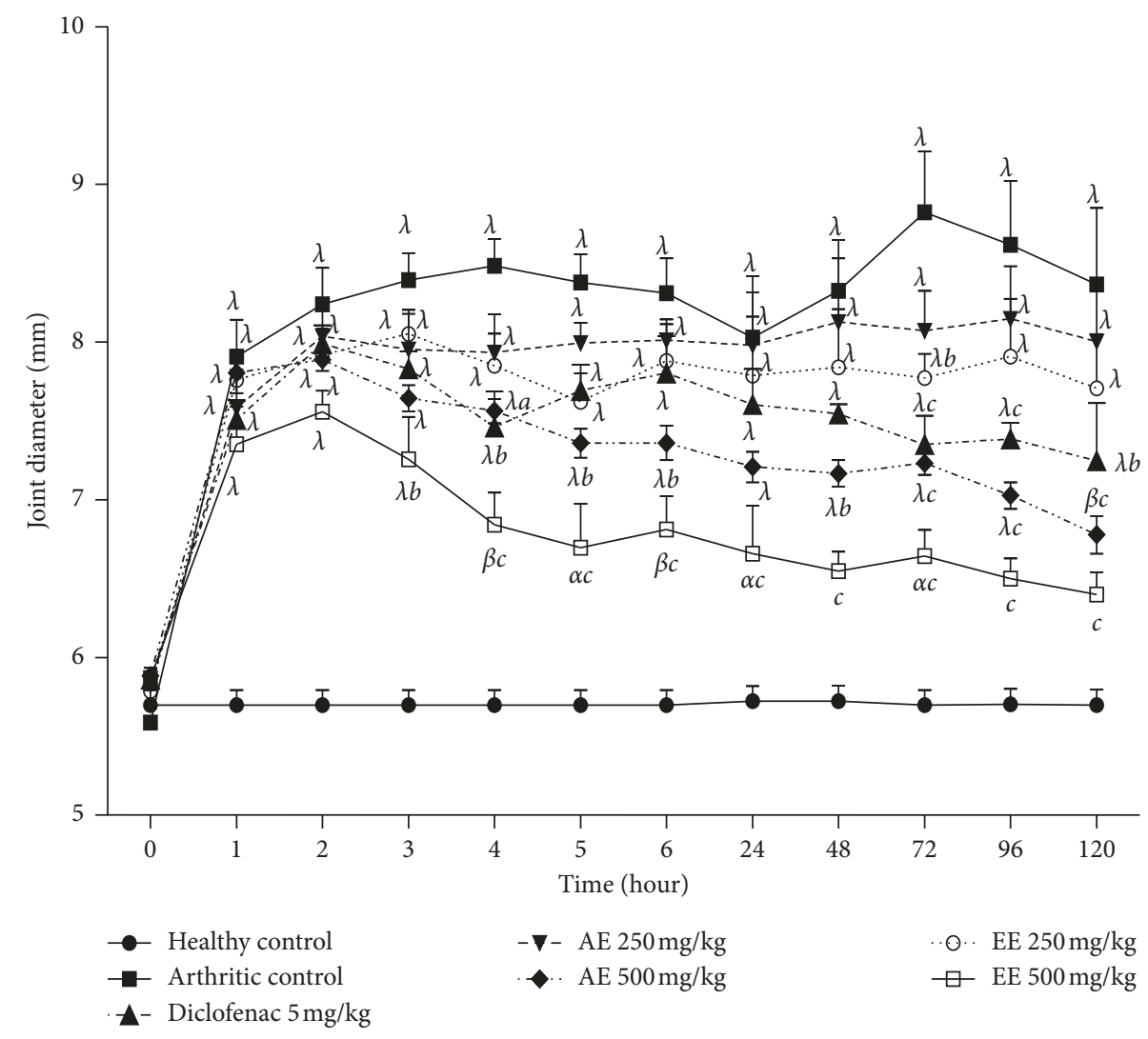

FIgURE 1: Effect of aqueous (AE) and ethanolic (EE) extracts of Dissotis thollonii on joint diameter in zymosan A-induced monoarthritis. Values are expressed as mean \pm SEM for six animals and analyses by two-way ANOVA followed by Bonferroni post hoc test, ${ }^{\alpha} p<0.05,{ }^{\beta} p<0.01$, and ${ }^{\lambda} p<0.001$ when compared with the healthy control and ${ }^{a} p<0.05,{ }^{b} p<0.01$, and ${ }^{c} p<0.001$ when compared with the arthritis control.

Figure 2 shows the histological analysis of the knee joints taken after injection of zymosan A. The architecture of the joint has a normal appearance in the nonarthritic control group; when in arthritic control, there is an erosion of the synovial membrane, a very large joint space, and erosion of bone and articular cartilage. However, treatment with aqueous and ethanolic extracts of $D$. thollonii prevented the destruction of the articular architecture of treated animals.

\subsection{Effect of D. thollonii Treatment on Polyarthritis Induced by CFA in Rats}

8.2.1. Effect of D. thollonii Treatment on Joint Diameter. After the injection of CFA into the tail, the diameter of the joint increased significantly on the 11th day after injection (Figure 3). Aqueous and ethanolic extracts $(500 \mathrm{mg} / \mathrm{kg}$ ) bring out the significative $(p<0.001)$ reduction of joint diameter from day 13 with inhibition percentages of $54.34 \%$ and $65.48 \%$, respectively, compared with the negative control. The inhibitory effect of different extracts remained significant during the days of experimentation. The maximum significant activity $(p<0.001)$ is observed at day 23 for diclofenac $(60.03 \%, 5 \mathrm{mg} / \mathrm{kg})$, at day 23 for the aqueous extract $(71.85 \%, 500 \mathrm{mg} / \mathrm{kg})$, and at the 31 st day for the ethanolic extract $(79.03 \%, 500 \mathrm{mg} / \mathrm{kg})$.
8.2.2. Effect of D. thollonii on Mechanical Nociceptive Pain Threshold. The induction of arthritis with CFA in rats generates the hypersensitivity threshold to mechanical pain which increased to day 10 still the end of experimentation $\left(34^{\text {th }}\right.$ day) with negative control. The continuous administration of different treatments significantly protected $(p<0.05, p<0.01$, and $p<0.001)$ animals against mechanical pain which was observed from the 10th day until the end of treatment. The maximal inhibitory activity is observed on the 12th day with the aqueous extract $(500 \mathrm{mg} /$ $\mathrm{kg}, p<0.001,69.00 \%)$, and on the 34 th day with the ethanolic extract $(500 \mathrm{mg} / \mathrm{kg}, p<0.001,70.35 \%)$ and at day 34 with diclofenac $(5 \mathrm{mg} / \mathrm{kg}, p<0.001,42.05 \%)$. However, there is little improvement observed with the aqueous extract $(250 \mathrm{mg} / \mathrm{kg})$ with respect to mechanical pain sensitivity threshold (Figure 4).

8.2.3. Effect of D. thollonii on Arthritic Score. The arthritic score does not materialize in normal controls, but in the groups that received CFA, it is very well materialized. Arthritic control groups are more affected from 11 until the end of treatment (Figure 5). Nevertheless, animals treated with different extracts showed a decrease in arthritic score values until the end of treatment. At the dose of $500 \mathrm{mg} / \mathrm{kg}$, ethanolic extract has more activity than the aqueous extract 


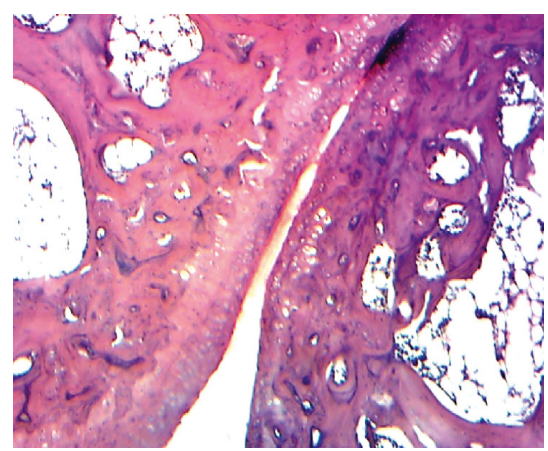

(a)

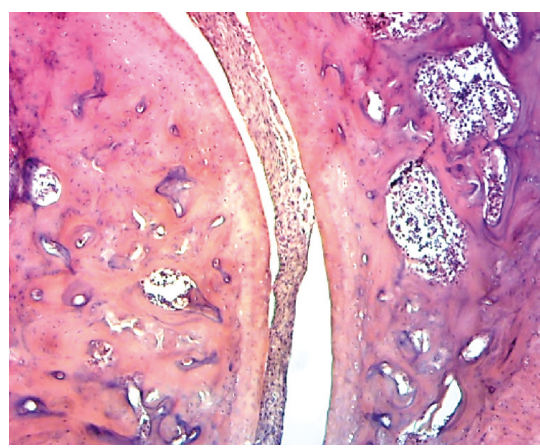

(c)

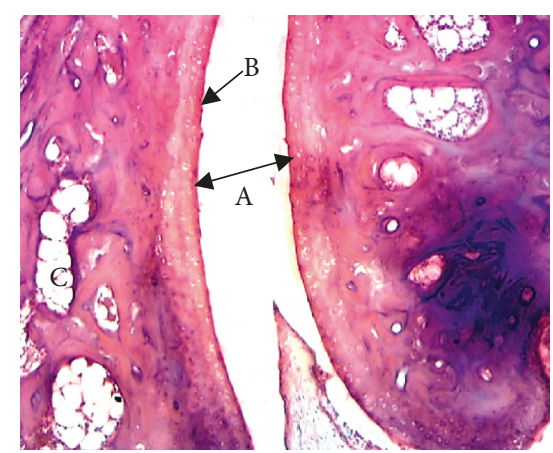

(b)

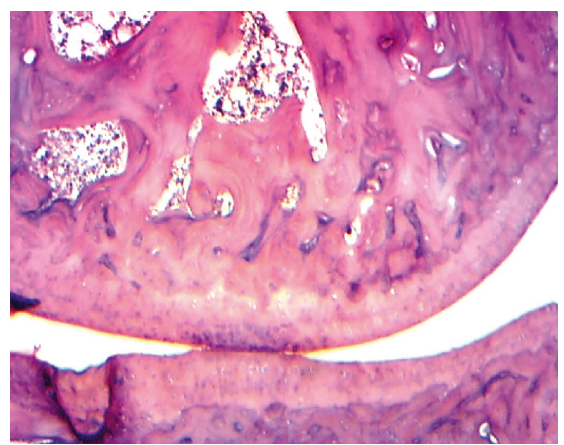

(d)

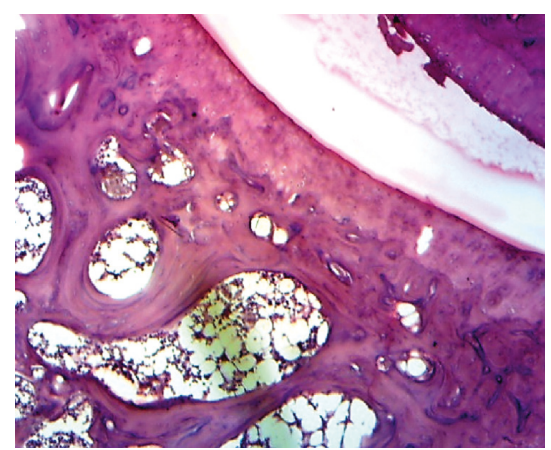

(e)

FIGURE 2: Histopathological analysis of ankle joints stained with H\&E. (a) Healthy control showing normal structure with small joint space; (b) Arthritic control showing very large joint space (A), erosion of articular cartilage (B), and bone erosion (C), (c) diclofenac $5 \mathrm{mg} / \mathrm{kg}$ treated, (d) aqueous extract (AE) $500 \mathrm{mg} / \mathrm{kg}$ treated, and (e) ethanolic extract (EE) $500 \mathrm{mg} / \mathrm{kg}$ treated showing a decrease in joint space, erosion of the synovial membrane and a reduction of erosion of articular cartilage.

because it has not only delayed the onset of arthritis materialization, but has also reduced the physical value of materialization. However, animals treated with diclofenac and ethanolic extract presented a significant $(p<0.001)$ reduction in the physical value of this materialization at the end of treatment.

8.2.4. Effect of D. thollonii on Body Weight and Organ Weight. In the arthritic control group, body weight decreased progressively and became significant $(p<0.01)$ from week 2 on positive group animals. In animals treated with the ethanolic extract $(500 \mathrm{mg} / \mathrm{kg})$, the change in body weight was significant $(p<0.05)$ at week 3 and persisted throughout treatment compared with arthritic control group animals. In animals from different groups treated with aqueous extract (500 and
$250 \mathrm{mg} / \mathrm{kg})$, with ethanolic extract $(250 \mathrm{mg} / \mathrm{mg})$, and with diclofenac $(5 \mathrm{mg} / \mathrm{kg})$, the change in body weight did not occur and was not significant $(p<0.05)$ throughout treatment (Figure 6).

Results showed that weights of the liver, spleen, and kidney increased significantly $(p<0.01)$, and the weight of thymus decreased significantly $(p<0.01)$ in all control animals arthritic compared with the healthy control group. Recovery of organ weight balance was observed with continuous administration of the different extracts in arthritic animals compared with negative control (Figure 7).

8.2.5. Effect of D. thollonii Extracts on Hematological Parameters. The results of the change in hematological parameters are shown in Table 4 . In animals in the arthritic 


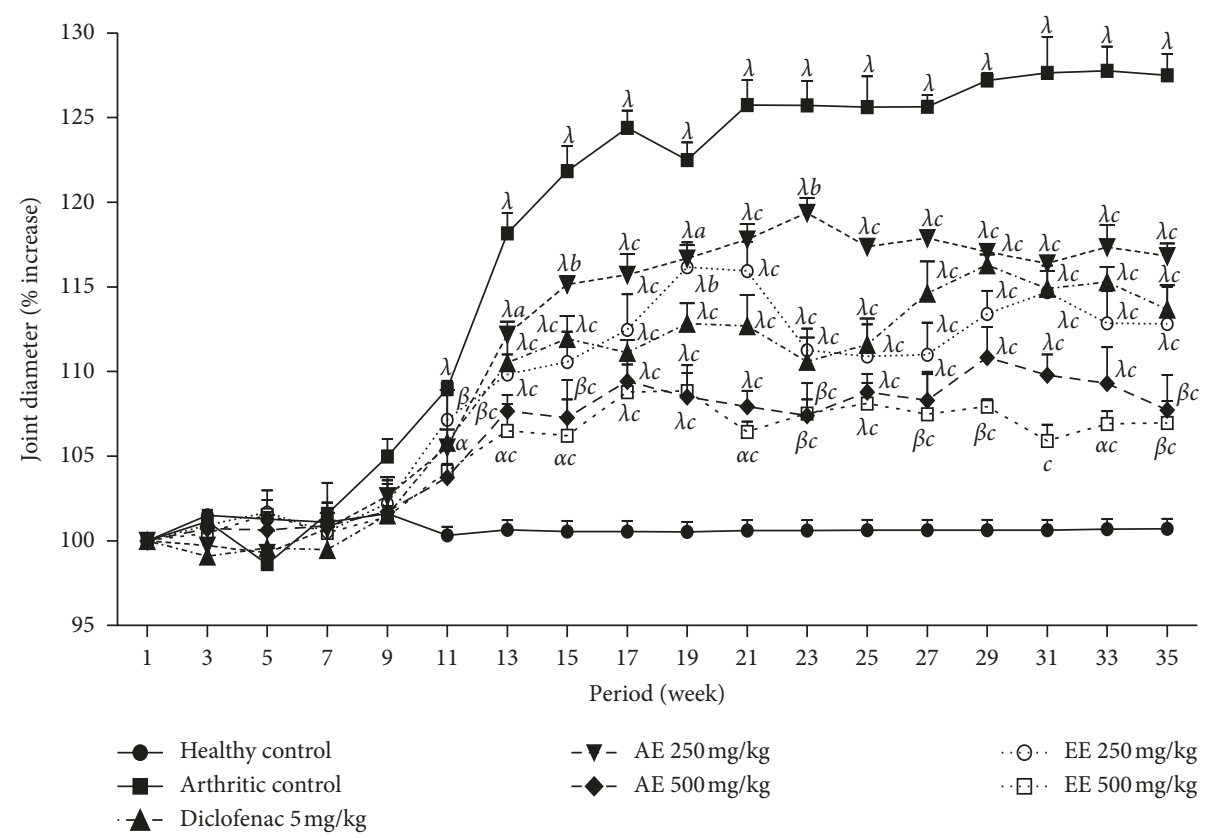

Figure 3: Effect of aqueous (AE) and ethanolic (EE) extracts of Dissotis thollonii on change in joint diameter in CFA-induced arthritis. Values are expressed as mean \pm SEM for six animals and analyses by two-way ANOVA followed by Bonferroni post hoc test, ${ }^{\alpha} p<0.05,{ }^{\beta} p<0.01$, and ${ }^{\lambda} p<0.001$ when compared with the healthy control and ${ }^{a} p<0.05,{ }^{b} p<0.01$, and ${ }^{c} p<0.001$ when compared with the arthritic control.

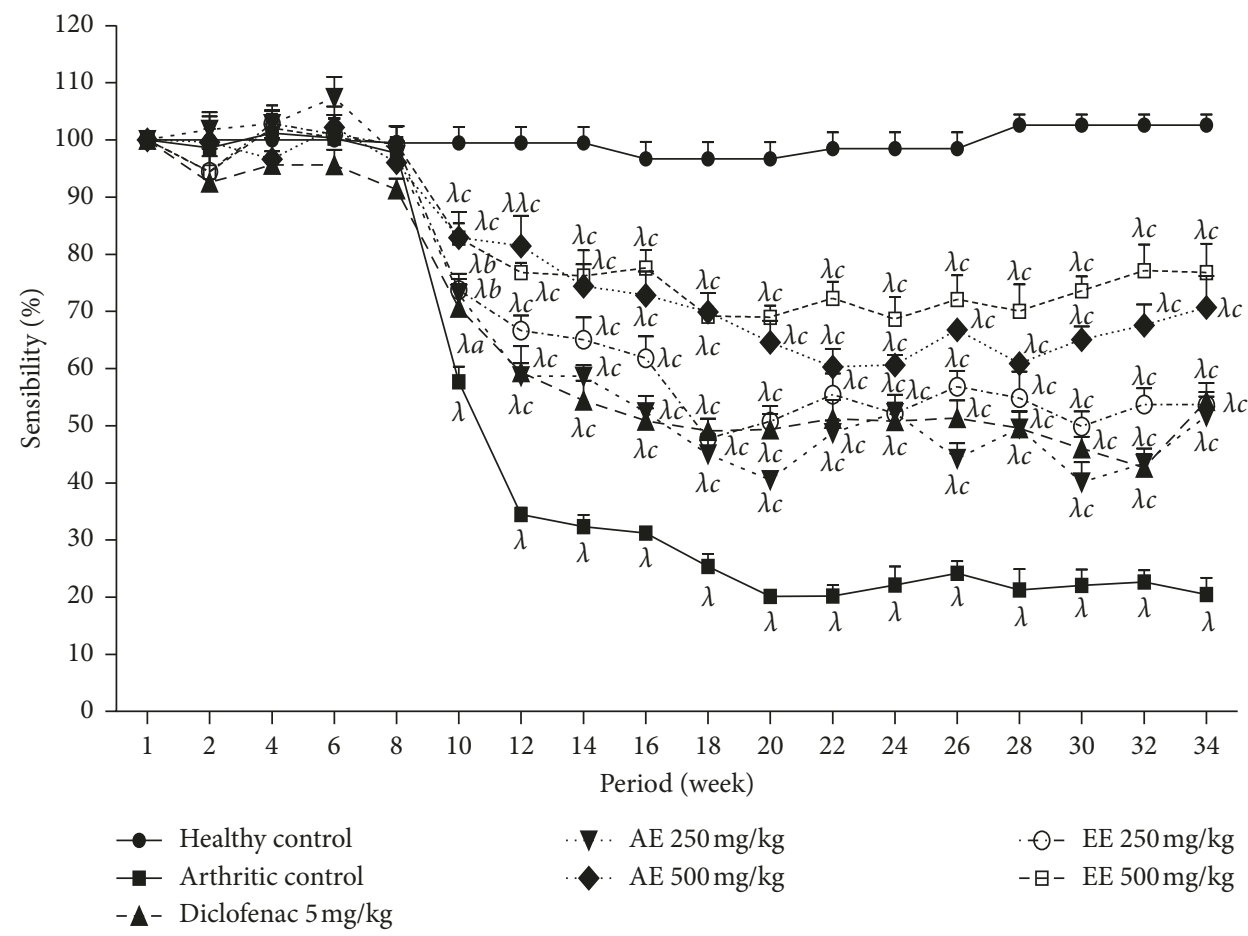

FIgURE 4: Effect of aqueous (AE) and methanolic (EE) extracts of Dissotis thollonii on mechanical hyperalgesia in CFA-induced arthritis. Values are expressed as mean \pm SEM for six animals and analyses by two-way ANOVA followed by Bonferroni post hoc test, ${ }^{\beta} p<0.01$ and $\lambda_{p}<0.001$ when compared with the healthy control and ${ }^{a} p<0.05,{ }^{b} p<0.01$, and ${ }^{c} p<0.001$ when compared with the arthritic control.

control group, platelet and $\mathrm{WBC}$ levels increased significantly $(p<0.001)$ in contrast to RBC, hemoglobin, and of hematocrit which decreased significantly $(p<0.001)$ compared with the healthy control. In treated animals with different doses of extracts (250 and $500 \mathrm{mg} / \mathrm{kg}$ ) and diclofenac $(5 \mathrm{mg} / \mathrm{kg})$, the various parameters evaluated are close to those of animals in the healthy control group. 


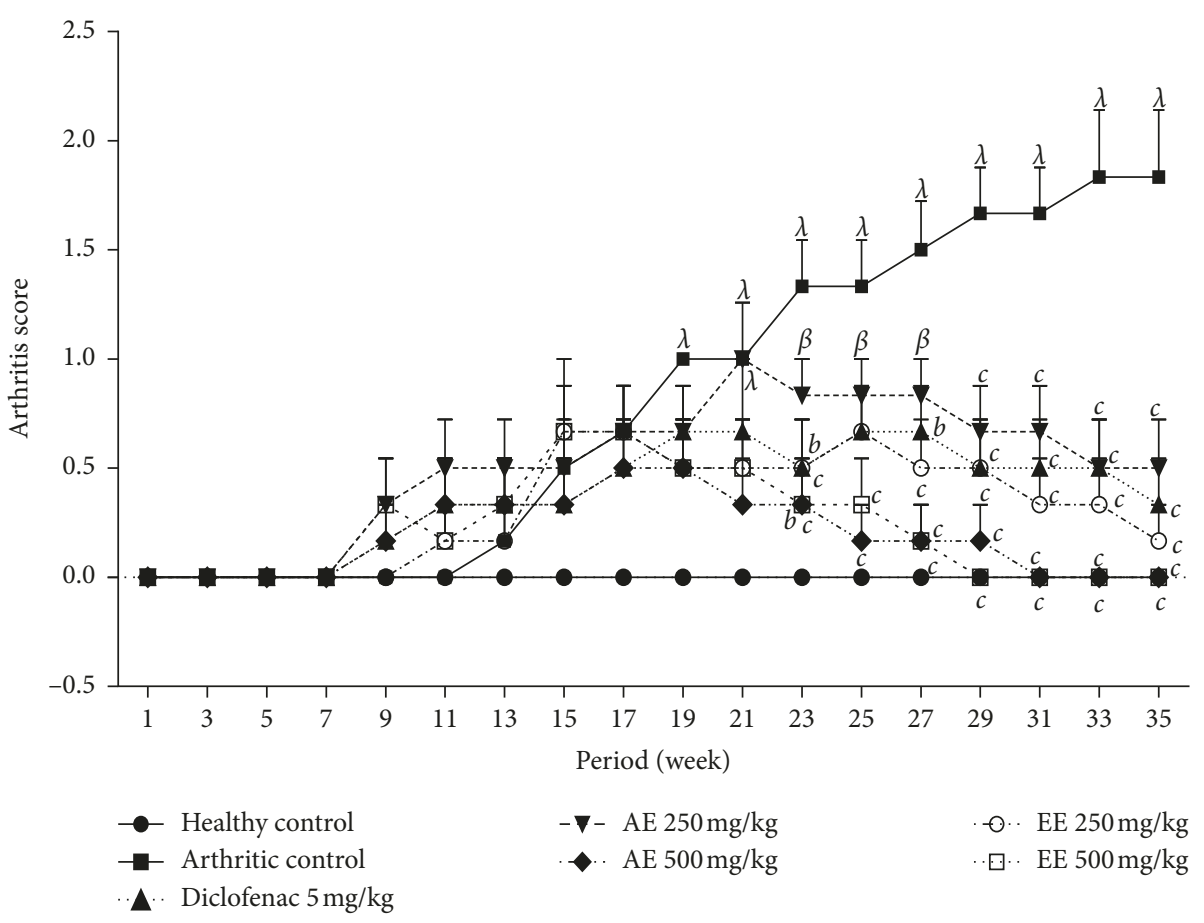

Figure 5: Effect of aqueous (AE) and ethanolic (EE) extracts of Dissotis thollonii on the arthritis score in CFA-induced arthritis. Values are expressed as mean \pm SEM for six animals and analyses by two-way ANOVA followed by Bonferroni post hoc test, ${ }^{\lambda} p<0.001$ when compared with the healthy control and ${ }^{b} p<0.01$ and ${ }^{c} p<0.001$ when compared with the arthritic control.

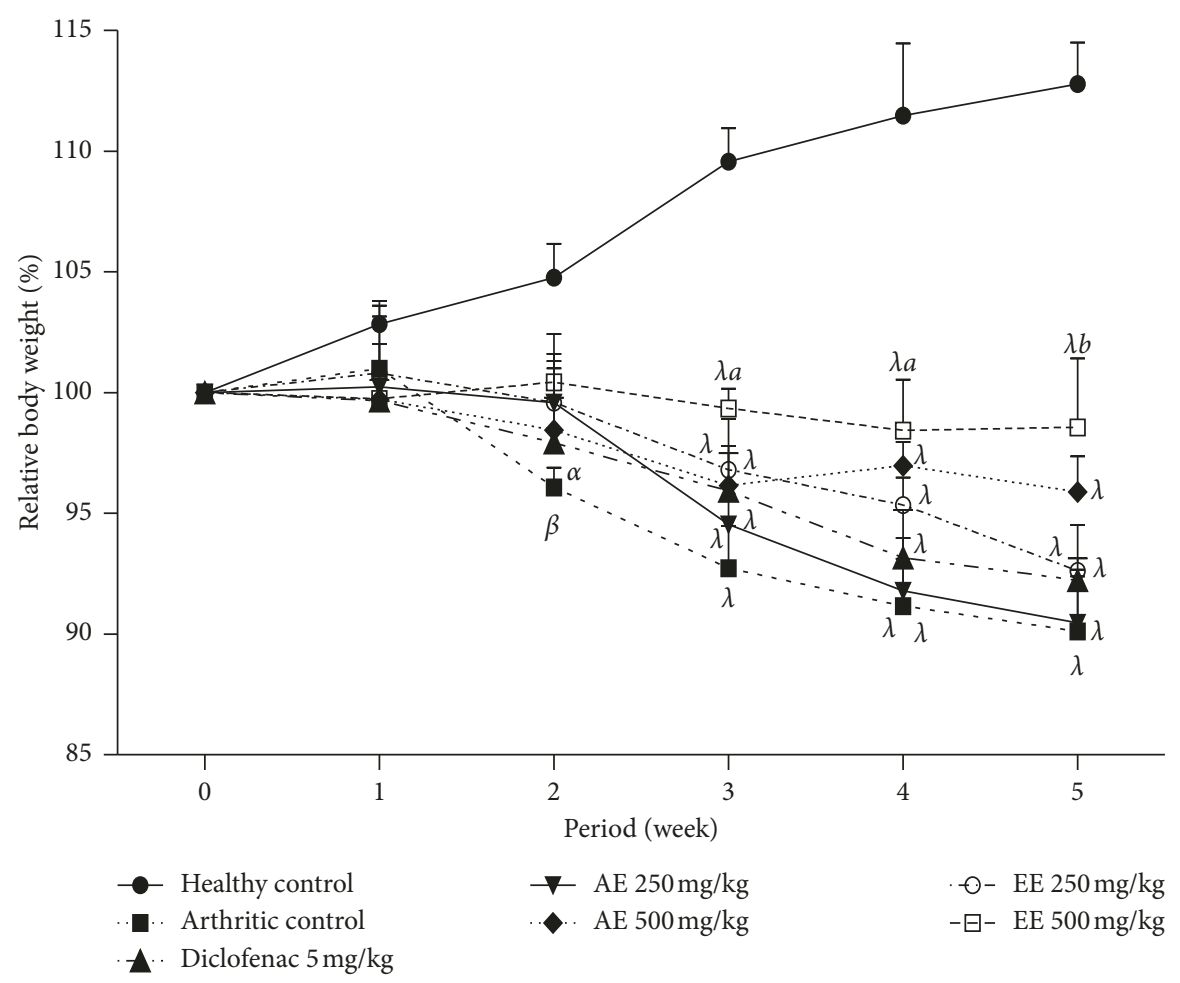

FIgURE 6: Effect of aqueous (AE) and ethanolic (EE) extracts of Dissotis thollonii on body weight in CFA-induced arthritis. Values are expressed as mean \pm SEM for six animals and analyses by two-way ANOVA followed by Bonferroni post hoc test, ${ }^{\alpha} p<0.05,{ }^{\beta} p<0.01$, and $\lambda_{p}<0.001$ when compared with the healthy control and ${ }^{a} p<0.05$ and ${ }^{b} p<0.01$ when compared with the arthritic control.

8.2.6. Effect of D. thollonii Extracts on Biochemical Parameters. The biochemical parameters are shown in Table 5. Serum levels in arthritic animals show a significant $(p<0.001)$ increase in AST, ALT, ALP, and creatinine and a significant decrease $(p<0.001)$ of total protein relative to the serum level of the healthy control. These different levels 


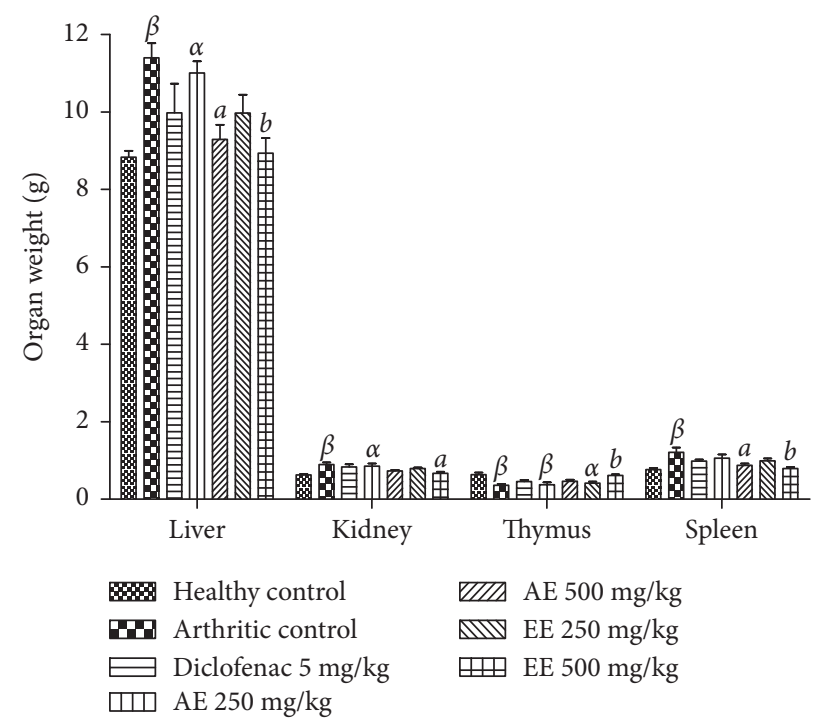

Figure 7: Effect of aqueous (AE) and ethanolic extracts (EE) of Dissotis thollonii on organ weight in CFA-induced arthritis. Values are expressed as mean \pm SEM for six animals and analyses by one-way ANOVA followed by Bonferroni post hoc test, ${ }^{\alpha} p<0.05$ and ${ }^{\beta} p<0.01$ when compared with the healthy control and ${ }^{a} p<0.05$ and ${ }^{b} p<0.01$ when compared with the arthritic control.

TABLE 4: Influence of the aqueous and ethanolic extracts of Dissotis thollonii on haematological in CFA-induced arthritis in rats.

\begin{tabular}{lcccccc}
\hline Treatment & Dose $(\mathrm{mg} / \mathrm{kg})$ & Haemoglobin $(\mathrm{g} / \mathrm{dl})$ & Hematocrit $(\%)$ & Platelet $\left(10^{9} / \mathrm{L}\right)$ & $\mathrm{RBC}(\mathrm{million} / \mu \mathrm{l})$ & WBC $\left(10^{9} / \mathrm{L}\right)$ \\
\hline Healthy control & - & $16.40 \pm 0.73$ & $38.78 \pm 1.03$ & $365.25 \pm 26.23$ & $7.22 \pm 0.34$ & $7.85 \pm 0.44$ \\
Arthritic control & - & $9.43 \pm 0.20^{\lambda}$ & $25.65 \pm 1.27^{\lambda}$ & $554.75 \pm 21.54^{\lambda}$ & $3.90 \pm 0.37^{\lambda}$ & $13.78 \pm 0.56^{\lambda}$ \\
Diclofenac & 5 & $14.15 \pm 0.62^{b}$ & $33.88 \pm 2.59^{a}$ & $481.75 \pm 13.31^{\beta}$ & $5.65 \pm 0.24^{a}$ & $10.63 \pm 0.64^{\alpha a}$ \\
& 250 & $14.28 \pm 0.67^{b}$ & $31.15 \pm 1.23^{\alpha}$ & $478.74 \pm 18.71^{\beta}$ & $5.74 \pm 0.40^{a}$ & $11.85 \pm 0.80^{\lambda}$ \\
Aqueous extract & 500 & $15.55 \pm 0.59^{c}$ & $37.73 \pm 1.28^{c}$ & $383.50 \pm 9.75^{c}$ & $6.93 \pm 0.25^{c}$ & $10.25 \pm 0.41^{b}$ \\
& 250 & $14.33 \pm 1.02^{b}$ & $32.20 \pm 1.70$ & $426.00 \pm 18.11^{c}$ & $6.31 \pm 0.38^{c}$ & $11.15 \pm 0.48^{\beta}$ \\
Ethanolic extract & 500 & $16.88 \pm 1.32^{c}$ & $38.38 \pm 0.99^{c}$ & $374.75 \pm 8.28^{c}$ & $7.36 \pm 0.29^{c}$ & $8.28 \pm 0.42^{c}$ \\
\hline
\end{tabular}

CFA: complete Freund's adjuvant; RBC: red blood cell; WBC: white blood cell. Each value represents the mean \pm ESM of six animals. ${ }^{\alpha} p<0.05 ;{ }^{\beta} p<0.01$; ${ }^{\lambda} p<0.001$ statistically significant compared with the healthy control. Each value represents the mean \pm ESM of 6 animals. ${ }^{a} p<0.05 ;{ }^{b} p<0.01 ;{ }^{c} p<0.001$ statistically significant compared to arthritic control.

TABLE 5: Effect of aqueous and ethanolic extracts of Dissotis thollonii on serum parameters in CFA-induced arthritis in rats.

\begin{tabular}{lcccccc}
\hline Treatment & Dose $(\mathrm{mg} / \mathrm{kg})$ & ALT $(\mathrm{U} / \mathrm{I})$ & AST $(\mathrm{U} / \mathrm{I})$ & ALP $(\mathrm{U} / \mathrm{I})$ & Creatinine $(\mu \mathrm{mol} / \mathrm{l})$ & Total protein $(\mathrm{g} / \mathrm{dl})$ \\
\hline Healthy control & - & $47.09 \pm 1.91$ & $173.89 \pm 11.61$ & $90.27 \pm 3.36$ & $0.48 \pm 0.07$ & $7.45 \pm 0.24$ \\
Arthritic control & - & $77.88 \pm 2.07^{\lambda}$ & $423.09 \pm 23.51^{\lambda}$ & $444.38 \pm 13.69^{\lambda}$ & $1.39 \pm 0.13^{\lambda}$ & $5.90 \pm 0.17^{\beta}$ \\
Diclofenac & 5 & $63.46 \pm 1.50^{\lambda c}$ & $250.70 \pm 16.76^{\beta c}$ & $240.11 \pm 16.28^{\lambda c}$ & $0.93 \pm 0.03^{\lambda c}$ & $6.65 \pm 0.28$ \\
Aqueous extract & 250 & $63.97 \pm 1.72^{\lambda c}$ & $299.79 \pm 11.76^{\lambda c}$ & $317.40 \pm 17.20^{\lambda c}$ & $0.98 \pm 0.05^{\lambda c}$ & $6.35 \pm 0.34$ \\
& 500 & $55.14 \pm 1.16^{\alpha c}$ & $222.59 \pm 6.07^{c}$ & $207.33 \pm 9.89^{\lambda c}$ & $0.69 \pm 0.03^{c}$ & $7.31 \pm 0.19^{a}$ \\
Ethanolic extract & 250 & $55.41 \pm 1.84^{\alpha c}$ & $253.30 \pm 2.77^{\beta c}$ & $270.97 \pm 7.43^{\lambda c}$ & $0.86 \pm 0.3^{\beta c}$ & $7.16 \pm 0.29^{a}$ \\
& 500 & $46.12 \pm 1.42^{c}$ & $177.62 \pm 7.62^{c}$ & $143.00 \pm 5.34^{c}$ & $0.60 \pm 0.02^{c}$ & $7.54 \pm 0.28^{b}$ \\
\hline
\end{tabular}

CFA: complete Freund's adjuvant; ALP: alkaline phosphatase; AST: aminotransferase; ALT: alanine aminotransferase. Each value represents the mean \pm ESM for six animals and analyses by one-way ANOVA followed by Bonferroni post hoc test, ${ }^{\alpha} p<0.05,{ }^{\beta} p<0.01,{ }^{\lambda} p<0.001$ when compared with the healthy control and ${ }^{a} p<0.05,{ }^{b} p<0.01,{ }^{c} p<0.001$ when compared with the arthritic control.

improved considerably in animals treated with different extracts (aqueous and ethanolic) and diclofenac.

8.2.7. Effect of D. thollonii Extracts on Oxidative Stress Parameters. The results on the change in oxidative stress parameters shown in Table 6 indicate that levels of $\mathrm{NO}$ and MDA increased significantly $(p<0.01)$ in arthritic animals, whereas levels of glutathione, catalase, and SOD decreased significantly $(p<0.01)$ compared with the healthy control. Animals treated with aqueous and ethanolic extracts, such as diclofenac, tend to improve these values.

8.2.8. Histopathological Study. A histopathological study of the knee joint showed no evidence of inflammation, bone erosion, cartilage destruction, or cellular infiltration in the healthy control. Animals in the arthritic control group 
TABLE 6: Effect of aqueous and ethanolic extracts of Dissotis thollonii on some parameters of oxidative stress in CFA-induced arthritis in rats.

\begin{tabular}{|c|c|c|c|c|c|c|}
\hline Treatment & Dose $(\mathrm{mg} / \mathrm{kg})$ & $\mathrm{NO}(\mu \mathrm{M})$ & Glutathion $\left(\times 10^{3}\right.$ activity $)$ & Catalase (activity) & $\mathrm{MDA}\left(\times 10^{3} \mathrm{~mol} / \mathrm{l}\right)$ & SOD (activity) \\
\hline Healthy control & - & $0.048 \pm 0.003$ & $0.28 \pm 0.03$ & $52.99 \pm 0.67$ & $0.087 \pm 0.021$ & $1.93 \pm 0.02$ \\
\hline Arthritic control & - & $0.089 \pm 0.003^{\lambda}$ & $0.17 \pm 0.01^{\beta}$ & $36.89 \pm 0.72^{\lambda}$ & $0.138 \pm 0.027$ & $1.51 \pm 0.03^{\lambda}$ \\
\hline Diclofenac & 5 & $0.044 \pm 0.001^{c}$ & $0.21 \pm 0.01$ & $37.72 \pm 0.74^{\gamma}$ & $0.112 \pm 0.035$ & $1.92 \pm 0.03^{c}$ \\
\hline \multirow{2}{*}{ Aqueous extract } & 250 & $0.073 \pm 0.005^{\lambda a}$ & $0.18 \pm 0.02^{\beta}$ & $45.33 \pm 0.97$ & $0.127 \pm 0.020$ & $1.93 \pm 0.02^{c}$ \\
\hline & 500 & $0.064 \pm 0.003^{\alpha c}$ & $0.24 \pm 0.01$ & $51.45 \pm 1.70^{c}$ & $0.109 \pm 0.038$ & $1.95 \pm 0.04^{c}$ \\
\hline \multirow{2}{*}{ Ethanolic extract } & 250 & $0.067 \pm 0.001^{\beta c}$ & $0.22 \pm 0.01$ & $48.95 \pm 1.18^{c}$ & $0.125 \pm 0.005$ & $1.94 \pm 0.02^{c}$ \\
\hline & 500 & $0.046 \pm 0.003^{c}$ & $0.27 \pm 0.01^{b}$ & $52.39 \pm 4.09^{c}$ & $0.071 \pm 0.020$ & $1.95 \pm 0.08^{c}$ \\
\hline
\end{tabular}

Each value represents the mean \pm ESM for six animals and analyses by one-way ANOVA followed by Bonferroni post hoc test, ${ }^{\alpha} p<0.05,{ }^{\beta} p<0.01$, and ${ }^{\lambda} p<0.001$ when compared with the healthy control and ${ }^{a} p<0.05,{ }^{c} p<0.001$ when compared with the arthritic control.

presented joint architecture exhibiting cartilage destruction, bone erosion, and cellular infiltration; but animals treated with different extracts $(250$ and $500 \mathrm{mg} / \mathrm{kg}$ ) and diclofenac $(5 \mathrm{mg} / \mathrm{kg}$ ) showed a significant protection of the architecture of the joint (Figure 8 ) by reducing bone erosion, cartilage destruction, and cellular infiltration.

\section{Discussion}

In the present study, the results show that aqueous and ethanolic extracts of $D$. thollonii have well anti-inflammatory properties in vitro in several models such as the inhibition of denaturation of proteins, 5-LOX, COX, and ROS. Inflammation, which is a very complex physiopathological response, involves the production of free radicals derived from neutrophils, NO, ROS, cytokines, and prostaglandins during its process [42]. Protein denaturation is the process by which proteins lose their tertiary structure and secondary structure. Proteins denaturation is a well-documented cause of inflammation [43]. The inflammation mechanism involves a series of events in which the metabolism of arachidonic acid plays an important role. Phenylbutazone, salicylic acid, flufenamic acid (anti-inflammatory drugs), etc., have shown a dose-dependent ability to thermally induced protein denaturation [44]. The pathogenesis of inflammatory diseases involves the overproduction of substances such as prostaglandin I2, thromboxane A2, prostaglandin E2, arachidonic acid, and leukotrienes through two metabolic pathways, the cyclooxygenase (COX) pathway and the 5-lipoxygenase (5-LOX) pathway [45]. In various inflammatory and allergic disorders, COX and 5LOX are the main enzymes in the synthesis of prostanoids and eicosanoids from polyunsaturated fatty acids. The effective reduction of chronic inflammatory conditions is important by double inhibition of LOX and COX [46]. Substances capable of producing double inhibition of COX and 5-LOX with consequent substantial reduction in leukotriene and prostaglandin production produce a broad spectrum of anti-inflammatory activity and can be considered to have an excellent profile of pharmacological safety in clinical practice [47]. The anti-inflammatory activity of the aqueous and ethanolic extract of $D$. thollonii was determined using two methods, which were cyclooxygenase- 2 (COX-2) and lipoxygenase (LOX) assays. All extracts tested showed significant activities vis-à-vis both tests. The inhibitory activity of aqueous and ethanolic extracts of $D$. thollonii on the denaturation of proteins, the cyclooxygenase and 5-lipoxygenase pathways, show that these two extracts are capable of significantly inhibiting the production of prostaglandins and leukotrienes, which gives these two extracts anti-inflammatory properties. These results are justified by the fact that compounds such as betulinic acid isolated from $D$. thollonii possess an in vitro inhibition property of cyclooxygenase (COX-1 and COX-2) and leukotriene B4 formation mediated by 5-LOX [48, 49].

The injection of zymosan into the knee joint causes a proliferative inflammatory monoarthritis resulting from the onset of an inflammatory reaction accompanied by hypernociception, an influx of neutrophils and leukocytes and then production by the infiltrated synovial cells and/or many inflammatory mediators include cytokines, free radicals, prostaglandins, and leukotrienes, which are responsible for the breakdown of articular cartilage, pannus formation, and synovial hypertrophy [50, 51]. Clinical management of arthritis is primarily aimed at reducing the intensity of pain, joint swelling, and then preventing or significantly reducing bone erosion and the various joint damages observed [52]. In this study, aqueous and ethanolic extracts of $D$. thollonii significantly reduced joint swelling up to the fifth hour of single administration, and the effect remains significant until the fifth day in continuous treatment. Similarly, the histological analysis of the joints has shown that the extracts of this plant, as well as diclofenac, induce a protective effect on the alteration of the synovial membrane, on bone erosion and considerably reduce cartilage lesions.

The caudal injection-induced polyarthritis of CFA in rats is a very good experimental model for preclinical evaluation of new antiarthritic agents; this model has many similarities with human rheumatoid diseases [53-55]. In addition, CFA injection induces hyperalgesia and allodynia by altering sensitivity to high-threshold nociceptor transduction [56]. In the present study, D. thollonii extracts showed an antiarthritic potential on all evaluated inflammatory parameters. These extracts significantly reduced the diameter of the joint in arthritic animals, and they significantly reduced the susceptibility of arthritic animals to mechanical pain, and they significantly improved the arthritic score. On these important parameters, the inhibitory effect of the extracts was significantly greater than that of diclofenac. In many disease states such as rheumatoid arthritis, decreased body weight is an important predictor of health [57]. The results of this study show that the extracts improved the body mass of the treated animals when compared with the untreated animals. During the development of rheumatoid arthritis, 


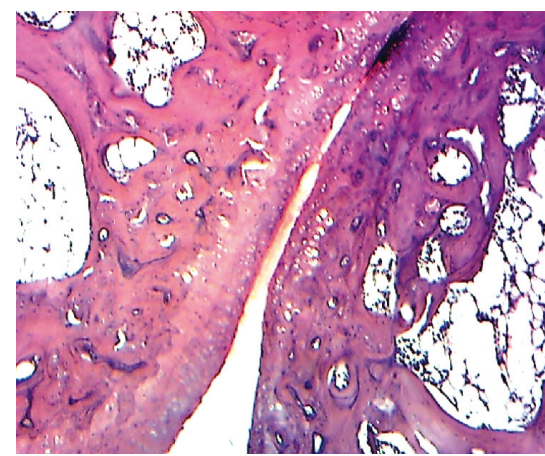

(a)

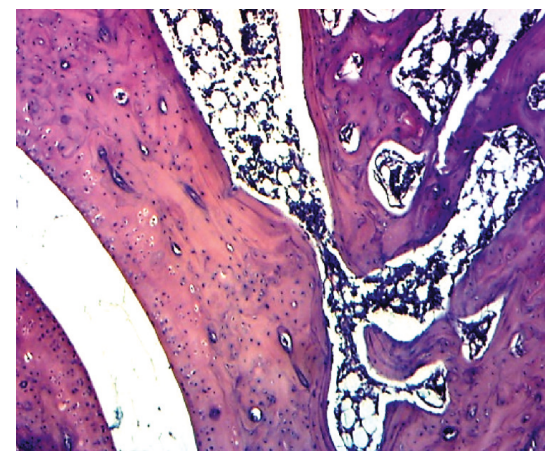

(c)

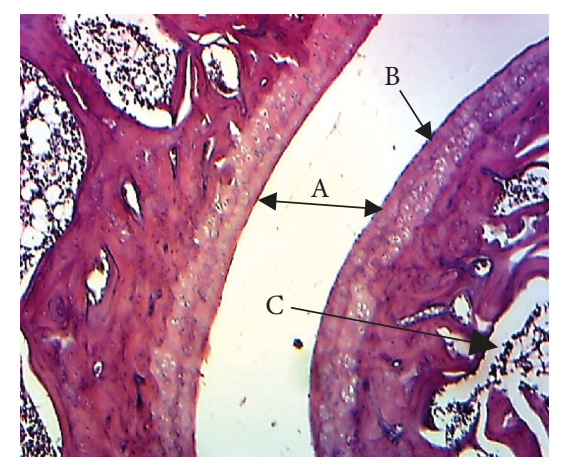

(b)

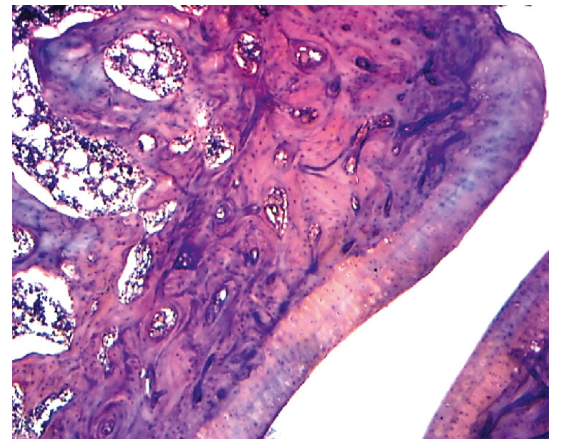

(d)

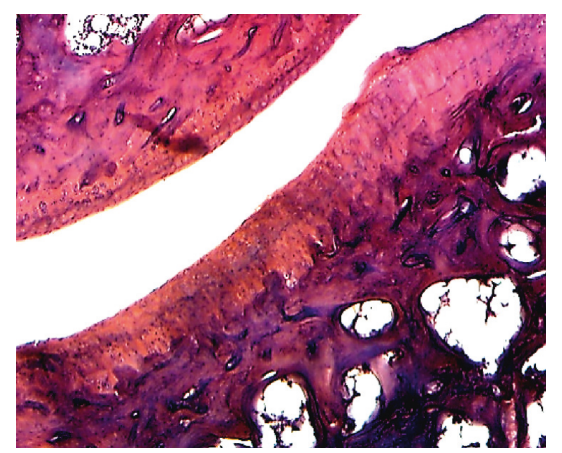

(e)

FIgURE 8: Histopathological analysis of ankle joints stained with H\&E. (a) Healthy control showing normal structure with small joint space; (b) arthritic control showing very large joint space (A), destruction of cartilage (B), bone erosion (C), and cellular infiltration (D); (c) diclofenac $5 \mathrm{mg} / \mathrm{kg}$ treated, (d) aqueous extract (AE) $250 \mathrm{mg} / \mathrm{kg}$ treated, and (e) ethanolic extract (EE) $250 \mathrm{mg} / \mathrm{kg}$ treated showing a decrease in joint space, a reduction of cells infiltration and reduction of cartilage destruction.

several enzymes are highlighted and represent good indices according to their importance (case of alkaline phosphatase and transaminases). The increase in serum levels of these enzymes would be implicated in periarticular osteopenia, in bone erosion and also indicate severe liver injury resulting in the production of biologically active substances in the inflammatory process [58-61]. In the present study, arthritic rat serum values ALP, AST, and ALT significantly increases, whereas in animals submited to different treatments (aqueous and ethanolic extracts of the leaves of D. thollonii or diclofenac) increased levels of these enzymes have been significantly reduced.

In the pathogenicity of rheumatoid arthritis, ROS, which are considered to be enhancers of inflammatory proliferation of the synovial membrane, play a key role in that their increased production increases the destruction of cartilage and even bones, activates or removes NF- $\kappa \mathrm{B}$ transcription factor, induces the production of many cytokines, and activates enzymes such as COX and 5-lipoxygenase or even inducible nitrogen monoxide [62-65]. The NF- $\kappa \mathrm{B}$ transcription factor is present in the cytosol of many cells where it is bound with the factor $I-k B$, especially those expressing cytokines, growth factors, chemokines, and adhesion molecules. Activation of the cell causes the phosphorylation of I-kB which is degraded followed by the release of the factor NF- $\kappa \mathrm{B}$, which is introduced into the nucleus of the cell and causes the transcription of many proinflammatory mediators including iNOS, COX-2, and TNF- $\alpha$ and IL- $1 \beta$, IL-6, and IL-8 [66]; thus, bone erosion and cartilage destruction observed in rheumatoid arthritis are due to overproduction of cytokines 
and inflammatory mediators. The aqueous and ethanolic extracts of the leaves of $D$. thollonii showed excellent antioxidant power, and in this study, the inhibition of the production of extracellular ROS in whole blood and in various phagocytic cells was significative (neutrophils and macrophages). This activity is thought to be due to the inhibition of pro inflammatory cytokine production (TNF alpha), the inhibition of denaturation of protein and the inhibition of the activity of proinflammatory enzymes such as COX and 5lipoxygenase.

To investigate the effect of aqueous and ethanolic extracts of the leaves of $D$. thollonii on another aspect of the cellular immune response, the assay on T-cell proliferation was used. The results show that these $D$. thollonii extracts significantly inhibit T-cell proliferation, with a very significant result for the extracts compared with prednisolone used as a positive control. The results suggest that the compounds present in $D$. thollonii extracts are capable of significantly modulating, at different stages, the immune response. The significant decrease in the diameter of the joints observed macroscopically and histopathologically, followed by a decreased insensitivity to pain, clearly reveals the anti-inflammatory, antihyperalgic, and antiarthritic potential of $D$. thollonii extracts. It is possible that the effect of our different extracts is associated with an inhibition of the phosphorylation of the transcription factor NF- $\kappa$ B. This is justified by the fact that compounds such as betulinic acid, ellagic acid, $\beta$-sitosterol, and ajuronic acid present in the extract of $D$. thollonii [30] have shown their ability to prevent degradation of the inhibitory $\mathrm{I} \kappa \mathrm{B}-\alpha$ protein, inducing inhibition of NF- $\kappa \mathrm{B}$ nuclear transcription factor activation, subsequent reduction of COX-2 expression, iNOS, inflammatory cell quantity, the levels of TNF- $\alpha$, IL-6, IL-8, and increase the production of IL-10 [67-72]. Given that, during the development of the inflammatory reaction, the stimulation of the production of TNF- $\alpha$, IL- $1 \beta$, NO, and PGE2 would be linked to the activation of the NF- $\kappa \mathrm{B} / \mathrm{I} \kappa \mathrm{B}-$ $\alpha$ axis [73]; thus, the suppression of this axis has a significant therapeutic effect [72]. In addition, D. thollonii extracts showed in vitro inhibitory effects on TNF- $\alpha$ production, intracellular ROS production, leukocyte migration, and cell-proliferative HeLa cell line [24].

\section{Conclusions}

At the end of this study, the conclusion that we can deduce is that $D$. thollonii is a plant containing several groups of chemical compounds with anti-inflammatory and antiarthritic potential. These properties have been evaluated by in vitro and in vivo studies. In vitro studies have shown that $D$. thollonii has a very strong anti-inflammatory property: inhibition of protein denaturation, inhibition of 5-LOX, inhibition of COX and ROS and in vivo studies that have shown antiarthritis activity of the plant on a zymosan-induced monoarthritis model and a model of CFA-induced polyarthritis in the rat. These results confirm the utilization of this plant in the traditional treatment of chronic inflammatory diseases and consider it a potential candidate for the isolation of new anti-inflammatory and/or antiarthritic products.

\section{Data Availability}

All data supporting our findings are adequately contained within the manuscript.

\section{Ethical Approval}

The experimental procedures have been approved by the local Ethics Committee and are in accordance with the guidelines for the study of pain in awake animals, published by the NIH (publication no. 85-23, "Principles of Animal Protection," Laboratory, Study of Pain, Ministry of Scientific Research and Technology, which adopted the European Union Guidelines on Animal Care and Experimentation (EWC 86/609).

For the donation of human blood samples, all processes of collecting blood are accepted by the Independent Ethics Committee, ICCBS, University of Karachi, $\mathrm{N}^{\circ}$ : ICCBS/IEC008-BC-2015/Protocol/1.0. The blood donors were provided informed approval for the use of their blood for the purposes of this study.

\section{Conflicts of Interest}

$\mathrm{MM}(\mathrm{PhD})$ is a Senior Lecturer in the Department of Animal Biology, Faculty of Science, University of Dschang, Cameroon. $\mathrm{AAD}(\mathrm{PhD})$ is a Senior Lecturer in the Department of Animal Biology, Faculty of Science, University of Yaounde 1, Cameroon. DNSF, TEG, YNW, MMMV, and ACF are PhD students in the Department of Animal Biology, Faculty of Science, University of Dschang, Cameroon. AG is an Associate Professor in the Department of Animal Biology, Faculty of Science, University of Dschang, Cameroon. The authors declare that they have no conflicts of interest.

\section{Authors' Contributions}

DNSF, MM, and AG designed the work. DNSF, MM, TEG, AAD, MMMV, and ACF conducted the work and collected and analysed the data. MM, NYW, AG, and AAD drafted the manuscript and revised it critically. All authors agree to be accountable for all aspects of the work.

\section{References}

[1] H. Jeon, W. J. Yoon, Y. M. Ham, S. A. Yoon, and S. C. Kang, "Anti-arthritis effect through the anti-inflammatory effect of Sargassum muticum extract in collagen-induced arthritic (CIA) mice," Molecules, vol. 24, no. 2, p. 276, 2019.

[2] E. H. Chou and G. S. Panayi, "Cytokine pathways and joint inflammation in rheumatoid arthritis," New England Journal of Medicine, vol. 344, no. 12, pp. 907-916, 2001.

[3] Y.-A. Lee, J. Y. Kim, S.-J. Hong et al., "Synovial proliferation differentially affects hypoxia in the joint cavities of rheumatoid arthritis and osteoarthritis patients," Clinical Rheumatology, vol. 26, no. 12, pp. 2023-2029, 2007.

[4] G. Murugananthan, K. G. Sudheer, C. P. Sathya, and S. Mohan, "Anti-arthritic and anti-inflammatory constituents 
from medicinal plants," Journal of Applied Pharmaceutical Science, vol. 3, no. 4, pp. 161-164, 2013.

[5] M. Feldmann, F. M. Brennan, and R. N. Maini, "Role of cytokines in rheumatoid arthritis," Annual Review of Immunology, vol. 14, no. 1, pp. 397-440, 1996.

[6] A. B. Irem, C. G. Ahmet, K. Hasan, and Y. Erdem, "Evaluation of the in vitro anti-inflammatory activity of Nerium oleander L. flower extracts and activity-guided isolation of the active constituents," Records of Natural Products, vol. 12, no. 2, pp. 128-141, 2018.

[7] C. Penido, F. P. Conte, M. S. S. Chagas, C. A. B. Rodrigues, J. F. G. Pereira, and M. G. M. O. Henriques, "Antiinflammatory effects of natural tetranortriterpenoids isolated from Carapa guianensis Aublet on zymosan-induced arthritis in mice," Inflammation Research, vol. 55, no. 11, pp. 457-464, 2006.

[8] J. C. da S Rocha, M. E. Peixoto, S. Jancar et al., "Dual effect of nitric oxide in articular inflammatory pain in zymosan induced arthritis in rats," British Journal of Pharmacology, vol. 136, no. 4, pp. 588-596, 2002.

[9] A. Bendele, "Animal models of rheumatoid arthritis," Journal Musculoskeletal Neuronal Interaction, vol. 1, no. 4, pp. 377385, 2001.

[10] R. Holmdahl, J. C. Lorentzen, S. Lu et al., "Arthritis induced in rats with non-immunogenic adjuvants as models for rheumatoid arthritis," Immunological Reviews, vol. 184, no. 1, pp. 184-202, 2001.

[11] H.-G. Schaible and B. D. Grubb, "Afferent and spinal mechanisms of joint pain,” Pain, vol. 55, no. 1, pp. 5-54, 1993.

[12] X. Cai, Y. F. Wong, H. Zhou et al., "The comparative study of sprague-dawley and lewis rats in adjuvant-induced arthritis," Naunyn Schmiedebergs Archives of Pharmacology, vol. 373, no. 2, pp. 140-147, 2006.

[13] B. Zhang, X.-L. He, Y. Ding, and G.-H. Du, "Gaultherin, a natural salicylate derivative from Gaultheria yunnanensis: towards a better non-steroidal anti-inflammatory drug," European Journal of Pharmacology, vol. 530, no. 1-2, pp. 166-171, 2006.

[14] A. R. Gaby, "Alternative treatments for rheumatoid arthritis," Alternative Medicine Review, vol. 4, no. 6, pp. 392-402, 1999.

[15] J. W. G. Jacobs, F. W. Kraaimaat, and J. W. J. Bijlsma, "Why do patients with rheumatoid arthritis use alternative treatments?," Clinical Rheumatology, vol. 20, no. 3, pp. 192-196, 2001.

[16] J. S. Bang, D. H. Oh, H. M. Choi et al., "Anti-inflammatory and antiarthritic effects of piperine in humaninterleukin $1 \beta$ stimulated fibroblast-like synoviocytes and in rat arthritis models," Arthritis Research \& Therapy, vol. 11, no. 2, pp. 1-9, 2009.

[17] M. Hegen, J. C. Keith, M. Collins, and C. L. Nickerson-Nutter, "Utility of animal models for identification of potential therapeutics for rheumatoid arthritis," Annals of the Rheumatic Diseases, vol. 67, no. 11, pp. 1505-1515, 2008.

[18] A. Okunlola and B. A. Adewoyin, O. A. Odeku, Evaluation of pharmaceutical and microbial qualities of some herbal medicinal products in South Western Nigeria," Tropical Journal of Pharmaceutical Research, vol. 6, no. 1, pp. 661-670, 2007.

[19] D. Susanti, H. M. Sirat, F. Ahmad, R. M. Ali, N. Aimi, and M. Kitajima, "Antioxidant and cytotoxic flavonoids from the flowers of Melastoma malabathricum L.," Food Chemistry, vol. 103, no. 3, pp. 710-716, 2007.

[20] J.-T. Cheng, F.-L. Hsu, and H.-F. Chen, "Antihypertensive principles from the leaves ofMelastoma candidum," Planta Medica, vol. 59, no. 5, pp. 405-406, 1993.
[21] T. Amalraj and S. Ignacimuthu, "Evaluation of the hypoglycaemic effect of Memecylon umbellatum in normal and alloxan diabetic mice," Journal of Ethnopharmacology, vol. 62, no. 3, pp. 247-250, 1998.

[22] D. S. Nicholl, H. M. Daniels, M. Ira Thabrew, R. J. Grayer, M. S. J. Simmonds, and R. D. Hughes, "In vitro studies on the immunomodulatory effects of extracts of Osbeckia aspera," Journal of Ethnopharmacology, vol. 78, no. 1, pp. 39-44, 2001.

[23] T. A. Abere, P. E. Okoto, and F. O. Agoreyo, "Antidiarrhoea and toxicological evaluation of the leaf extract of Dissotis rotundifoliatriana (Melastomataceae)," BMC Complementary and Alternative Medicine, vol. 10, no. 1, p. 71, 2010.

[24] H. TadjouaTchoumbou, G. Ateufack, W. Yousseu Nana et al., "Antidiarrhoeal, anti-inflammatory and cytotoxic effects of aqueous and methanolic leaves extract of Dissotis thollonii Cogn. (Melastomataceae)," European Journal of Pharmaceutical and Medical Research, vol. 5, no. 6, pp. 306-314, 2018.

[25] H. A. Loigier, Descriptive Flora of Puerto Rico and Adjacent Islands: Spermaphyta, Editorial de la Universidad de Puerto Rico, San Juan, Puerto Rico, 1994.

[26] IPNI, The International Plant Names Index, International Plant Names Index, Cambridge, MA, USA, 2012.

[27] D. S. Tala, S. P. C. Fodouop, D. N. Tsafack, N. Kodjio, C. Fokunang, and D. Gatsing, "Toxicological investigations of ethanolic leaves extract of dissothis thollonii (Melastomataceae)," Journal of Pharmaceutical Research International, vol. 24, no. 4, pp. 1-14, 2018.

[28] T. H. Tadjoua, G. Ateufack, U. S. Shabana et al., "Antidiarrhoeal, antibacterial activities and growth stimulatory effect on some probiotic organisms of aqueous and methanol leaves extract of Dissotis thollonii," Journal of Chemical and Pharmaceutical Research, vol. 9, no. 10, pp. 95-105, 2017.

[29] G. Ateufack, T. H. Tadjoua, N. W. Yousseu, S. F. Leonard, J. R. Kuate, and A. Kamanyi, “Antidiarrhoeal and antibacterial activity of aqueous and methanolic leaves extracts of Dissotis thollonii Cogn.(Melastomataceae)," Asian Pacific Journal of Tropical Biomedicine, vol. 4, no. 2, pp. S672-S678, 2014.

[30] R. N. Nono, L. Barboni, R. B. Teponno et al., "Antimicrobial, antioxidant, anti-inflammatory activities and phytoconstituents of extracts from the roots of Dissotis thollonii Cogn. (Melastomataceae)," South African Journal of Botany, vol. 93, pp. 19-26, 2014.

[31] M. Mbiantcha, E. G. Tsafack, G. Ateufack et al., "Analgesic, anti-inflammatory and anti-arthriticproperties of aqueous and methanolic stem bark extracts from Nauclea pobeguinii (Rubiacee) in rats," Journal of Complementary and Integrative Medicine, vol. 15, no. 4, pp. 1-9, 2018.

[32] M. Mbiantcha, J. Almas, A. D. Atsamo et al., "Anti-inflammatory and anti-arthritic effects of methanol extract of the stem bark of boswellia dalzielii hutch (Burseraceae) in rats," Inflammopharmacology, vol. 26, no. 6, pp. 1383-1398, 2018.

[33] F. J. A. Matos, Introducao à Fitoqu'rmica Experimental, Edicoes UFC, Fortaleza, Brazil, 2nd edition, 1997.

[34] P. Padmanabhan and S. N. Jangle, "Evaluation of in-vitro antiinflammatory activity of herbal preparation, a combination of four medicinal plants," International Journal of Basic and Applied Medical Sciences, vol. 2, no. 1, pp. 109-116, 2012.

[35] G. Elias and M. N. Rao, "Inhibition of albumin denaturation and anti-inflammatory activity of dehydrozingerone and its analogs," Indian Journal of Experimental Biology, vol. 26, no. 10 , pp. $540-542,1988$.

[36] V. Viji and A. Helen, "Inhibition of lipoxygenases and cyclooxygenase- 2 enzymes by extracts isolated from Васора 
monniera (L.) wettst," Journal of Ethnopharmacology, vol. 118, no. 2, pp. 305-311, 2008.

[37] M. Zimmerman, "Ethical guidelines for investigations of experimental pain in conscious animals," Pain, vol. 16, no. 2, pp. 109-110, 1983.

[38] M. Mesaik, Z. Zaheerulhaq, S. Murad et al., "Biological and molecular docking studies on coagulin-H: human IL-2 novel natural inhibitor," Molecular Immunology, vol. 43, no. 11, pp. 1855-1863, 2006.

[39] M. F. Mahomoodally, A. Gurib-Fakim, and A. H. Subratty, "Effect of exogenous ATP on Momordica charantia Linn. (Cucurbitaceae) induced inhibition of d-glucose, l-tyrosine and fluid transport across rat everted intestinal sacs in vitro," Journal of Ethnopharmacology, vol. 110, no. 2, pp. 257-263, 2007.

[40] M. Mbiantcha, J. Almas, U. S. Shabana, D. Nida, and F. Aisha, "Anti-arthritic property of crude extracts of Piptadeniastrum africanum (Mimosaceae) in complete Freund's adjuvant-induced arthritis in rats," BMC Complementary and Alternative Medicine, vol. 17, no. 1, pp. 1-16, 2017.

[41] C. Rita, V. Bruno, R. Helena et al., "Potent anti-inflammatory and antiproliferative effects of gambogic acid in a rat model of antigen-induced arthritis," Mediators of Inflammation, vol. 2014, Article ID 195327, 7 pages, 2014.

[42] M. M. Mannan, M. Maridass, and B. Victor, "A review on the potential uses of ferns," Ethnobotanical Leaflets, vol. 12, no. 24, pp. 281-285, 2008.

[43] M. V. Anoop and A. R. Bindu, "In-vitro anti-inflammatory activity studies on Syzygium zeylanicum (L) DC leaves," International Journal of Pharmacology Research\& Review, vol. 4, no. 8, pp. 18-27, 2015.

[44] Y. Mizushima and M. Kobayashi, "Interaction of anti-inflammatory drugs with serum proteins, especially with some biologically active proteins," Journal of Pharmacy and Pharmacology, vol. 20, no. 3, pp. 169-173, 1968.

[45] G. Ghosh, P. Panda, M. Rath, A. Pal, T. Sharma, and D. Das, "GC-MS analysis of bioactive compounds in the methanol extract of Clerodendrum viscosum leaves," Pharmacognosy Resarch, vol. 7, no. 1, pp. 110-113, 2015.

[46] G. de Gaetano, M. B. Donati, and C. Cerletti, "Prevention of thrombosis and vascular inflammation: benefits and limitations of selective or combined COX-1, COX-2 and 5-LOX inhibitors," Trends in Pharmacological Sciences, vol. 24, no. 5, pp. 245-252, 2003.

[47] F. M. Frey and R. Meyers, "Antibacterial activity of traditional medicinal plants used by Haudenosaunee peoples of New York State," BMC Complementary and Alternative Medecine, vol. 10, no. 1, p. 64, 2010.

[48] E. M. Wenzig, U. Widowitz, O. Kunert et al., "Phytochemical com-position and in vitro pharmacological activity of two rose hip (Rosa caninaL.) preparations," Phytomedicine, vol. 15, no. 10, pp. 826-835, 2008.

[49] G. M. Mansour, B. H. A. Faujan, and S. K. Alireza, "Biological activity of betulinic acid: a review," Pharmacology \& Pharmacy, vol. 3, no. 2, pp. 119-123, 2012.

[50] L. A. Darren, M. M. Ashley, B. M. Iain, and Y. L. Foo, “Animal models of rheumatoid arthritis," European Journal of Immunology, vol. 39, no. 8, pp. 2040-2044, 2009.

[51] F. A. da Rocha, M. M. Teixeira, J. C. Rocha et al., "Blockade of leukotriene B4 prevents articular incapacitation in rat zymosan-induced arthritis," European Journal of Pharmacology, vol. 497, no. 1, pp. 81-86, 2004.
[52] K. D. Tripathi, Essentials of Medical Pharmacology, Jaypee Brothers Medical Publishers, Ajanta Offset and Packagings Ltd., New Delhi, India, 6th edition, 2008.

[53] D. N. Benslay and A. M. Bendele, "Development of a rapid screen for detecting and differentiating immunomodulatory vs. anti-inflammatory compounds in rats," Agents and Actions, vol. 34, no. 1-2, pp. 254-256, 1991.

[54] F. C. Colpaert, T. Meert, P. De Witte, and P. Schmitt, "Further evidence validating adjuvant arthritis as an experimental model of chronic pain in the rat," Life Sciences, vol. 31, no. 1, pp. 67-75, 1982.

[55] S. Singh and D. K. Majumdar, "Effect of fixed oil of ocimum sanctum against experimentally induced arthritis and joint edema in laboratory animals," International Journal of Pharmacognosy, vol. 34, no. 3, pp. 218-222, 1996.

[56] M. Higgins, R. D’Agostino, W. Kannel, and J. Cobb, “Benefits and adverse effects of weight loss: observations from the framingham study," Annals of Internal Medicine, vol. 119, no. 7_Part_2, pp. 758-763, 1993.

[57] E. M. Glenn, J. Gray, and W. Kooyers, "Chemical changes in adjuvant induced polyarthritis of rats," American Journal of Veterinary Research, vol. 26, no. 114, pp. 1195-1203, 1965.

[58] Y. Niino-Nanke, H. Akama, M. Hara, and S. Kashiwazaki, "Alkaline phasphatase (ALP) activity in rheumatoid arthritis (RA): its clinical significance and synthesis of ALP in RA synovium," Ryumachi, vol. 38, no. 4, pp. 581-588, 1998.

[59] Q. Rehman and N. E. Lane, "Bone loss. Therapeutic approaches for preventing bone loss in inflammatory arthritis," Arthritis Research, vol. 3, no. 4, pp. 221-227, 2001.

[60] S. Aida, "Alkaline phosphatase isoenzyme activities in rheumatoid arthritis: hepatobiliary enzyme dissociation and relation to disease activity," Annals of the Rheumatic Diseases, vol. 52, no. 7, pp. 511-516, 1993.

[61] C. A. Hitchon and H. S. El-Gabalawy, "Oxidation in rheumatoid arthritis," Arthritis Research \& Therapy, vol. 6, no. 6, pp. 265-278, 2004.

[62] J. Almas, M. A. Mesaik, U. S. Shabana, S. B. Lubna, and F. Shaheen, "Anti-TNF- $\alpha$ and antiarthritis of patuletin: a rare flavonoid from Tagetes patula," International Immunopharmacology, vol. 36, pp. 232-240, 2016.

[63] J. Almas, Study of the suppression of inflammatory arthritis at molecular level by natural and synthetic inhibition of TNF $\alpha$ and $I L-1 \beta$, Ph.D thesis, p. 190, 2013.

[64] L. Zhou, W. Meng, C. Lvyi, X. Guangjimg, L. Xiao, and Z. Xiuqiao, "Role of sinomenine on complete freund's adjuvand-induced arthritis in rats," International Union of Biochemistory and Molecular Biology Life, vol. 68, no. 6, pp. 429-435, 2016.

[65] S. Guan, B. Fang, B. Song, Y. Xiong, and J. Lu, "Immunosuppressive activity of alpinetin on activation and cytokines secretion of murine T lymphocytes," Immunopharmacology and Immunotoxicology, vol. 36, no. 4, pp. 290-296, 2014.

[66] S. Guan, Y. Zheng, X. Yu, W. Li, B. Han, and J. Lu, "Ellagic acid protects against LPS-induced acute lung injury through inhibition of nuclear factor kappa B, proinflammatory cytokines and enhancement of interleukin-10," Food and Agricultural Immunology, vol. 28, no. 6, pp. 1347-1361, 2017.

[67] M. A. Rosillo, M. Sanchez-Hidalgo, A. Cárdeno, and C. Alarcón de la Lastra, "Protective effect of ellagic acid, a natural polyphenolic compound, in a murine model of Crohn's disease," Biochemical Pharmacology, vol. 82, no. 7, pp. 737-745, 2011.

[68] T. Hemalatha, S. Pulavendran, C. Balachandran, B. M. Manohar, and R. Puvanakrishan, "Arjuronic acid: a novel phytomedicine 
with multifunctional therapeutic applications," Indian Journal of Experimental Biology, vol. 48, no. 3, pp. 238-247, 2010.

[69] Y. Takada and B. B. Aggarwal, "Betulinic acid suppresses carcinogen-induced NF- $\kappa$ B activation through inhibition of $\mathrm{I} \kappa \mathrm{B}-\alpha$ kinase and p65 phosphorylation: abrogation of cyclooxygenase-2 and matrix metalloprotease-9," The Journal of Immunology, vol. 171, no. 6, pp. 3278-3286, 2003.

[70] T. Rabi, S. Shukla, and S. Gupta, "Betulinic acid suppresses constitutive and TNF $\alpha$-induced NF- $\kappa \mathrm{B}$ activation and induces apoptosis in human prostate carcinoma PC-3 cells," Molecular Carcinogenesis, vol. 47, no. 12, pp. 964-973, 2008.

[71] K.-A. Kim, I.-A. Lee, W. Gu, S. R. Hyam, and D.-H. Kim, " $\beta$-Sitosterol attenuates high-fat diet-induced intestinal inflammation in mice by inhibiting the binding of lipopolysaccharide to toll-like receptor 4 in the NF- $\kappa \mathrm{B}$ pathway," Molecular Nutrition \& Food Research, vol. 58, no. 5, pp. 963-972, 2014.

[72] S. G. Harris, J. Padilla, L. Koumas, D. Ray, and R. P. Phipps, "Prostaglandins as modulators of immunity," Trends in Immunology, vol. 23, no. 3, pp. 144-150, 2002.

[73] S. Dudhgaonkar, A. Thyagarajan, and D. Sliva, "Suppression of the inflammatory response by triterpenes isolated from the mushroom Ganoderma lucidum," International Immunopharmacology, vol. 9, no. 11, pp. 1272-1280, 2009. 


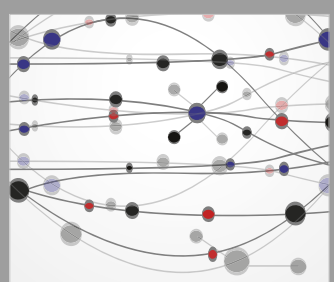

The Scientific World Journal
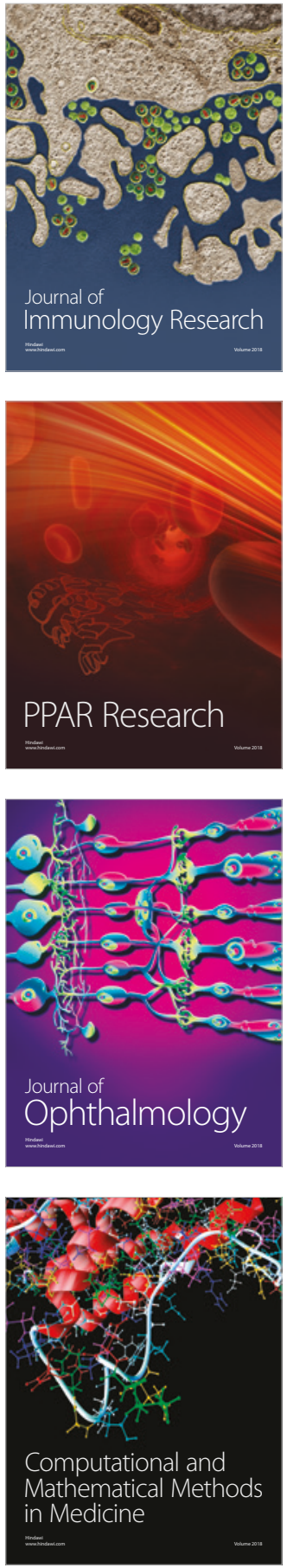

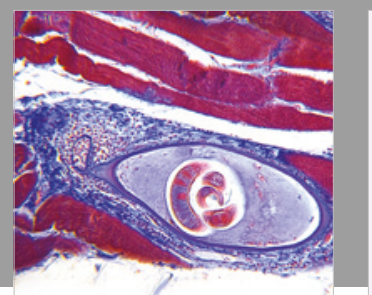

Gastroenterology Research and Practice

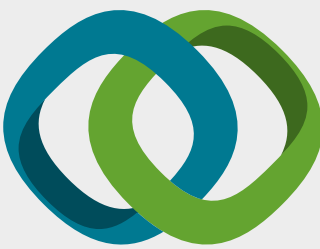

\section{Hindawi}

Submit your manuscripts at

www.hindawi.com
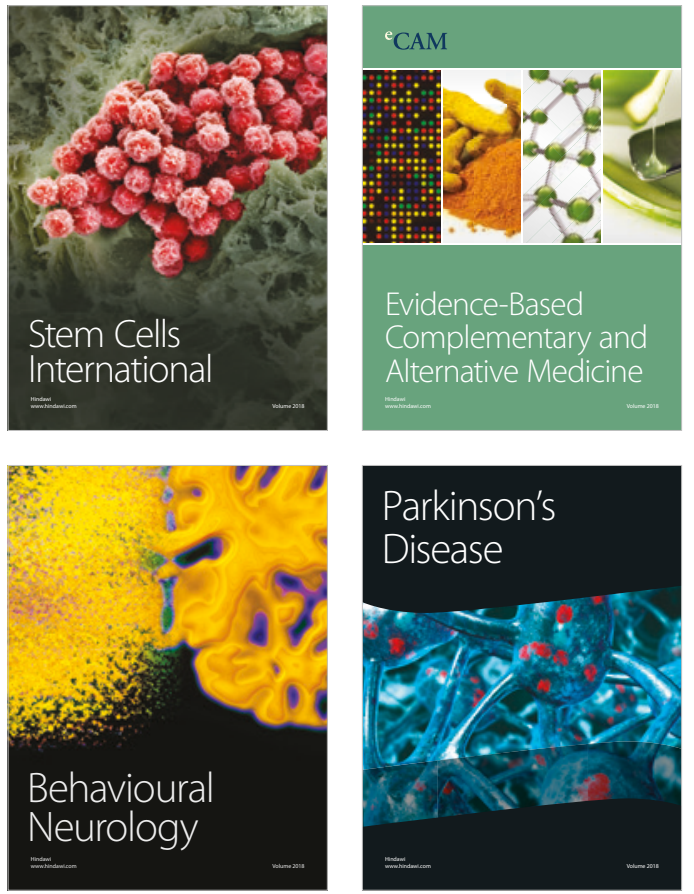

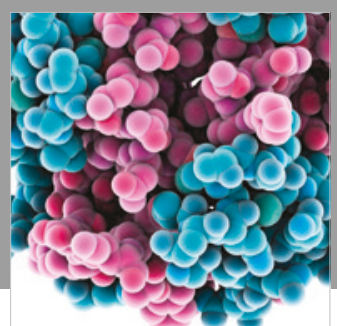

ournal of

Diabetes Research

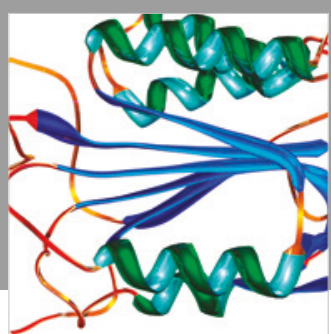

Disease Markers
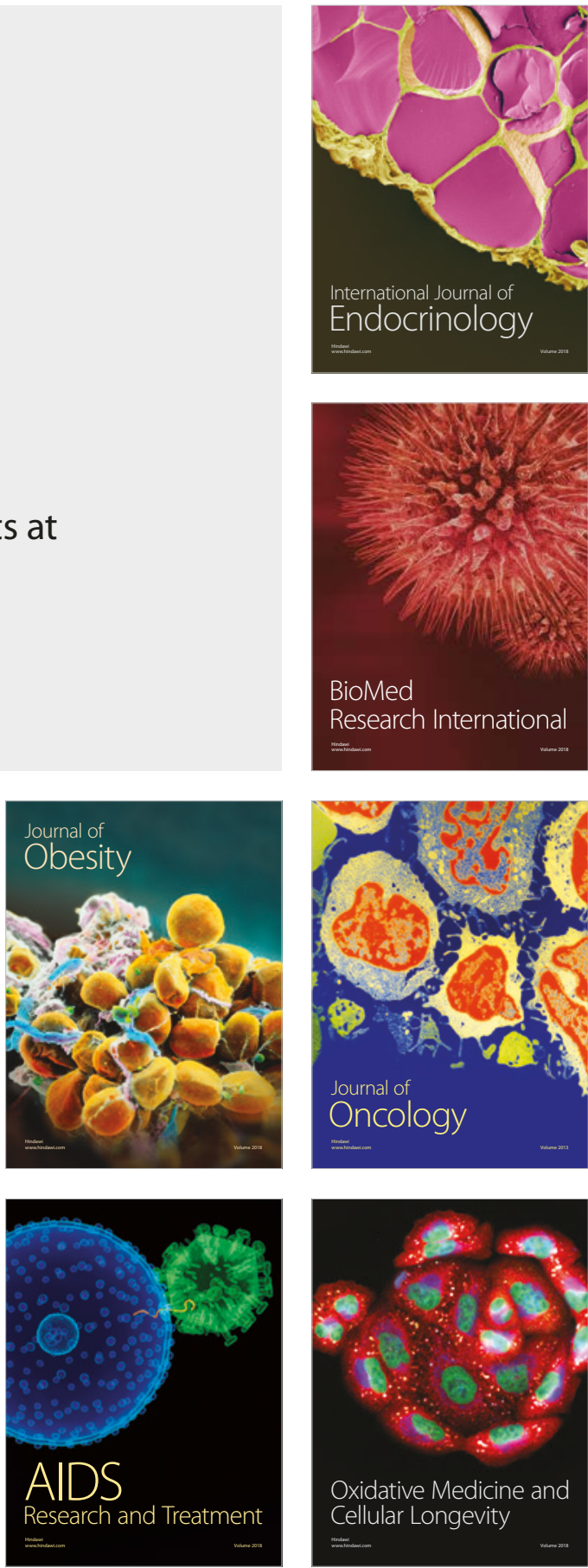